\title{
Neuronal Dysfunction in iPSC-Derived Medium Spiny Neurons from Chorea-Acanthocytosis Patients Is Reversed by Src Kinase Inhibition and F-Actin Stabilization
}

\author{
Nancy Stanslowsky, ${ }^{1 *}$ Peter Reinhardt, ${ }^{3 *}$ Hannes Glass, ${ }^{4}$ Norman Kalmbach, ${ }^{1}$ Maximilian Naujock, ${ }^{1,7}$ Niko Hensel, ${ }^{2}$ \\ Verena Lübben, ${ }^{2}$ Arun Pal, ${ }^{3,4,5}$ (D) Anna Venneri, ${ }^{1}$ Francesca Lupo, ${ }^{8}$ Lucia De Franceschi, ${ }^{8}$ Peter Claus, ${ }^{2}$ \\ Jared Sterneckert, ${ }^{3}$ Alexander Storch, ${ }^{3,4,5,9}$ Andreas Hermann, ${ }^{3,4,5,6 \dagger}$ and Florian Wegner, ${ }^{1,7 \dagger}$ \\ ${ }^{1}$ Department of Neurology and ${ }^{2}$ Institute of Neuroanatomy, Hannover Medical School, 30625 Hanover, Germany, ${ }^{3}$ Center for Regenerative Therapies \\ Dresden, ${ }^{4}$ Division of Neurodegenerative Diseases, Department of Neurology, ${ }^{5}$ German Center for Neurodegenerative Diseases Dresden, and ${ }^{6}$ Universitäts \\ Centrum für seltene Erkrankungen, Technische Universität Dresden, 01307 Dresden, Germany, ${ }^{7}$ Center for Systems Neuroscience, 30559 Hannover, \\ Germany, ${ }^{8}$ Department of Medicine, University of Verona and AOUI Verona, Policlinico GB Rossi, 37134 Verona, Italy, and ${ }^{9}$ Department of Neurology, \\ University of Rostock, Rostock, Germany
}

Chorea-acanthocytosis (ChAc) is a fatal neurological disorder characterized by red blood cell acanthocytes and striatal neurodegeneration. Recently, severe cell membrane disturbances based on depolymerized cortical actin and an elevated Lyn kinase activity in erythrocytes from ChAc patients were identified. How this contributes to the mechanism of neurodegeneration is still unknown. To gain insight into the pathophysiology, we established a ChAc patient-derived induced pluripotent stem cell model and an efficient differentiation protocol providing a large population of human striatal medium spiny neurons (MSNs), the main target of neurodegeneration in ChAc. Patient-derived MSNs displayed enhanced neurite outgrowth and ramification, whereas synaptic density was similar to controls. Electrophysiological analysis revealed a pathologically elevated synaptic activity in ChAc MSNs. Treatment with the F-actin stabilizer phallacidin or the Src kinase inhibitor PP2 resulted in the significant reduction of disinhibited synaptic currents to healthy control levels, suggesting a Src kinase- and actin-dependent mechanism. This was underlined by increased G/F-actin ratios and elevated Lyn kinase activity in patient-derived MSNs. These data indicate that F-actin stabilization and Src kinase inhibition represent potential therapeutic targets in ChAc that may restore neuronal function.

Key words: actin cytoskeleton; chorea-acanthocytosis; human induced pluripotent stem cells; patch-clamp electrophysiology; Src kinase; striatal medium spiny neurons

Significance Statement

Chorea-acanthocytosis (ChAc) is a fatal neurodegenerative disease without a known cure. To gain pathophysiological insight, we newly established a human in vitro model using skin biopsies from ChAc patients to generate disease-specific induced pluripotent stem cells (iPSCs) and developed an efficient iPSC differentiation protocol providing striatal medium spiny neurons. Using patch-clamp electrophysiology, we detected a pathologically enhanced synaptic activity in ChAc neurons. Healthy control levels of synaptic activity could be restored by treatment of ChAc neurons with the F-actin stabilizer phallacidin and the Src kinase inhibitor PP2. Because Src kinases are involved in bridging the membrane to the actin cytoskeleton by membrane protein phosphorylation, our data suggest an actindependent mechanism of this dysfunctional phenotype and potential treatment targets in ChAc.

\section{Introduction}

Neuroacanthocytosis (NA) syndromes are characterized by progressive degeneration of the basal ganglia and abnormal spiny red blood cells called acanthocytes. The core NA syndromes are the autosomal-recessive chorea-acanthocytosis (ChAc) and the $\mathrm{X}$-linked McLeod syndrome, with an estimated prevalence of $<1-5$ per 1,000,000 inhabitants of the general world population (Danek et al., 2001; Al-Asmi et al., 2005; Dobson-Stone et al., 
2005; Jung et al., 2011; Hermann and Walker, 2015). ChAc is described as a progressive hyperkinetic movement disorder with cognitive dysfunction, behavioral abnormalities, and variable acanthocytosis of red blood cells. In the progression of the disease, most patients develop a characteristic phenotype including chorea, a "feeding dystonia" with tongue protrusions (Bader et al., 2010), orofacial dyskinesia, involuntary vocalizations, dysarthria, and involuntary tongue and lip biting. ChAc is associated with epileptic seizures often appearing as initial symptoms in adolescence and additional multisystem features including myopathy and axonal neuropathy of variable degree. Cerebral magnetic resonance imaging may demonstrate striatal atrophy. The disease course usually begins in the second to the third decade and progresses chronically to major disability and premature death of the patient due to various complications after 15-30 years (Jung et al., 2011). There is currently only symptomatic treatment available.

ChAc is caused by mutations in the VPS13A gene leading to a loss of the protein chorein that is expressed in various cell types (Ueno et al., 2001; Velayos-Baeza et al., 2004). Chorein is a very large protein suggested to be involved in vacuolar protein sorting and morphogenetic membrane regulation in yeast (Ueno et al., 2001; Velayos-Baeza et al., 2004; Park and Neiman, 2012). The insufficient pathophysiological knowledge regarding ChAc relates to the lack of specific chorein antibodies and the limited availability of suitable (especially mammalian) animal models (Tomemori et al., 2005). Western blots for chorein demonstrate absence of this protein in red blood cells of ChAc patients (Dobson-Stone et al., 2002, 2004, 2005). Despite the identification of causative mutations in the VPS13A gene several years ago, the detailed function of the encoded protein and the mechanisms by which the disease-specific mutations cause neurodegeneration remain unclear. The association of the acanthocytic membrane abnormality with neurodegeneration, however, suggests a common pathogenetic pathway.

Recently, severe actin-related cell membrane disturbances and elevated Lyn kinase activity in erythrocytes from ChAc patients have been identified (De Franceschi et al., 2011a; Föller et al., 2012; Schmidt et al., 2013; Honisch et al., 2015). Actin negatively regulates vesicle fusion, as demonstrated by experiments in which depolymerization of cortical actin stimulates exocytosis in a variety of non-neuronal cell types (Burgoyne and Cheek, 1987; Muallem et al., 1995; Vitale et al., 1995). The polymerized form of actin, filamentous or F-actin, is the major cytoskeletal element identified in presynaptic nerve terminals (Fifková and Delay, 1982; Gotow et al., 1991). In cultured hippocampal neurons, F-actin depolymerization by latrunculin A increases exocytosis rapidly by a mechanism independent of intracellular $\mathrm{Ca}^{2+}$. These findings indicate that either actin itself or proteins that link to the actin cytoskeleton participate in a regulatory mechanism that

Neuroacanthocytosis Patients; Andreas Niesel for his excellent technical support; and Carola Kassebaum for technical assistance.

The authors declare no competing financial interests.

*N.S. and P.R. contributed equally to this work.

†A.H. and F.W. are co-senior authors.

P. Reinhardt's present address: Neuroscience Discovery, Biology Department, AbbVie Deutschland GmbH \& Co. KG, 67061 Ludwigshafen, Germany.

A. Storch's present address: Department of Neurology, University of Rostock, and German Center for Neurodegenerative Diseases (DZNE) Rostock, 18051 Rostock, Germany.

Correspondence should be addressed to Prof. Dr. med. Florian Wegner, Department of Neurology, Hannover Medical School, Carl-Neuberg-Str. 1, 30625 Hannover, Germany. E-mail: Wegner.Florian@mh-hannover.de.

DOI:10.1523/JNEUROSCI.0456-16.2016

Copyright $\odot 2016$ the authors $\quad 0270-6474 / 16 / 3612028-17 \$ 15.00 / 0$ restrains fusion of synaptic vesicles at the active zone (Morales et al., 2000).

To investigate pathophysiological mechanisms, we established a human in vitro model of ChAc using reprogrammed skin fibroblasts from patients to generate disease-specific induced pluripotent stem cells (iPSCs). We hypothesized that a disturbed actin polymerization in ChAc leads to a pathological synaptic hyperactivity preceding degeneration of striatal GABAergic interneurons. Therefore, we developed an efficient iPSC differentiation protocol providing a large number of striatal medium spiny neurons (MSNs) and performed detailed functional analyses of voltage- and ligand-gated ion channels and synaptic activity of disease-specific neurons and healthy controls to identify potential therapeutic targets for the treatment of ChAc.

\section{Materials and Methods}

Induction, cultivation, and three-germ-layer differentiation of human iPSCs (hiPSCs). Skin biopsy of lines not published previously was taken after informed consent according to the approval of the ethical committee of the Medical Faculty of the Technische Universität Dresden (EK 45022009). Human dermal fibroblasts (HDFs) of two female ChAc patients (born 1977 and 1962), referred to as mutant (Mut), as well as HDFs from healthy sex- and age-matched control persons (born 1965 and 1959) referred to as wild-type (WT), were reprogrammed to iPSCs as described previously (Reinhardt et al., 2013a). Briefly, HDFs were retrovirally transduced with OCT4, SOX2, KLF4, and $c-M Y C$. After $14-21 \mathrm{~d}$, emerging iPSC colonies were isolated clonally and further cultivated.

hiPSCs were cultivated on mitomycin C (Tocris Bioscience)inactivated mouse embryo fibroblast feeder cells in human embryonic stem cell (hESC) medium, which consisted of knock-out DMEM (Life Technologies), 20\% knock-out serum replacement (Life Technologies), $0.1 \mathrm{~mm} \beta$-mercaptoethanol, $1 \%$ penicillin/streptomycin/glutamine (PSG), $1 \%$ nonessential amino acids, and $5 \mathrm{ng} / \mathrm{ml}$ human FGF2 (Peprotech). iPSCs were passaged every $5-7 \mathrm{~d}$ using $1 \mathrm{mg} / \mathrm{ml}$ collagenase IV or dispase (both from Life Technologies).

For three-germ-layer differentiation, iPSCs were detached from the feeder layer as colonies to form embryoid bodies (EBs) using $2 \mathrm{mg} / \mathrm{ml}$ collagenase IV for $45 \mathrm{~min}$. Colony pieces were collected by sedimentation and resuspended in hESC medium without FGF2 supplemented with 1 $\mu \mathrm{M}$ dorsomorphin (Tocris Bioscience), $10 \mu \mathrm{M}$ SB-431542 (Abcam), and $5 \mu \mathrm{M}$ Y27632 Rho-kinase (ROCK) inhibitor, and plated onto non-cellculture-treated plastic Petri dishes to form EBs. Two and $4 \mathrm{~d}$ later, the medium was changed to hESC medium without any additional supplements. Six days later, EBs were either plated on Matrigel (BD Biosciences)-coated plastic dishes in N2B27 medium (see below) for ectoderm formation or on gelatin (Sigma-Aldrich)-coated plates in DMEM with $1 \%$ PSG and 20\% fetal calf serum (Biochrom) for mesoderm and endoderm differentiation. The medium was changed every $3 \mathrm{~d}$ and cells were fixed and analyzed by immunocytochemistry after 2 weeks.

Differentiation of striatal MSNs. To differentiate hiPSCs into MSNs, colonies were detached from the feeder layer using collagenase or dispase 2-3 d after splitting to form EBs. Detached colonies were collected by sedimentation and resuspended in hESC medium without FGF2, supplemented with $1 \mu \mathrm{M}$ dorsomorphin, $10 \mu \mathrm{M}$ SB-431542, $1 \mu \mathrm{M}$ IWP2 (Millipore), and $5 \mu \mathrm{M}$ Y27632 ROCK inhibitor, and plated on non-cellculture-treated plastic Petri dishes to prevent cell attachment (day 0). Two days later, the medium was replaced with a 1:1 mixture of hESC and N2 medium (DMEM/F-12, with 1:100 N2 supplement, both Life Technologies, $1 \%$ PSG), supplemented with the same concentrations of dorsomorphin, SB-431542, and IWP2 as mentioned above (day 2). Two days later, the medium was changed to N2 medium with the same combination of small molecules (day 4). On days 6 and 8, the medium was replaced with $\mathrm{N} 2$ medium containing $0.6 \mu \mathrm{M}$ purmorphamine (PMA; Alexis) and $1 \mu \mathrm{M}$ IWP2. On day 10, small-molecule supplements were withdrawn and, on days 12-14, EBs were plated on Matrigel-coated plates (Corning) in N2B27 maturation medium (1:1 DMEM/F-12 and Neurobasal medium containing 1:200 N2, 1:100 B27 without vitamin A, 
all from Life Technologies, and 1\% PSG), supplemented with $20 \mathrm{ng} / \mathrm{ml}$ brain-derived neurothropic factor (BDNF), $10 \mathrm{ng} / \mathrm{ml}$ glial cell linederived neurotrophic factor (GDNF), $1 \mathrm{ng} / \mathrm{ml}$ transforming growth factor- $\beta 3$ (TGF $\beta 3$ ) (all from Peprotech), and 0.5 mm dibutyryl-cAMP (dbcAMP; Sigma-Aldrich). The medium was changed every other day. Once the outgrowing cells became too confluent (days 20-24), cells were replated. Cultures were treated for $2 \mathrm{~min}$ with fresh, prewarmed Accutase (Sigma-Aldrich), washed once with PBS and N2B27 each, and detached in maturation medium with a cell scraper. After pipetting to break the cell clusters into smaller clumps, cells were replated at a 1:3 ratio on fresh Matrigel-coated plates in maturation medium. To replate the cultures as single cells at $\sim$ day 30 or at earlier time points, as indicated, neuronal cultures were digested using fresh, warm Accutase supplemented with $10 \mu \mathrm{M}$ Y27632 ROCK inhibitor for up to $1 \mathrm{~h}$. Cultures were carefully pipetted to a single-cell suspension, diluted at least 1:10 in N2B27 medium with ROCK inhibitor, collected by centrifugation for $5 \mathrm{~min}$ at $200 \times g$, and replated in maturation medium with ROCK inhibitor. ROCK inhibitor was withdrawn the day after splitting.

Cell quantification after long-term cell culture. Mature MSNs were differentiated for at least 3 months ( 4 separate experiments using 5 healthy control and 4 ChAc clones). Cells were washed once with PBS and then treated with Accutase for $1 \mathrm{~h}$. The reaction solution was then diluted with DMEM/F12, centrifuged at $200 \times g$ for $4 \mathrm{~min}$, the supernatant discarded, and the pellet resuspended in a 1:1 mixture of DMEM/F12 and Neurobasal medium without phenol red. Cells were gently triturated to yield a homogeneous suspension. The solution was incubated with $7.5 \mu \mathrm{g} / \mathrm{ml}$ Hoechst33342 (Life Technologies) and analyzed with excitation at 360 $\mathrm{nm}$ and measuring emission at $460 \mathrm{~nm}$ using a GENios fluorescence microplate reader (Tecan) and Magellan version 7.2 software (Tecan). Background values were obtained by measuring $7.5 \mu \mathrm{g} / \mathrm{ml}$ Hoechst 33342 in cell-free solution and deducted from the samples. Quantification was done relative to healthy controls and a Student's $t$ test with $p<0.05$ considered significant.

Differentiation of midbrain dopaminergic neurons. iPSCs were converted into neural precursor cells that could be maintained independently and propagated to yield a homogeneous starting condition for differentiation into tyrosine hydroxylase-positive midbrain dopaminergic neurons (mDANs), as described previously (Reinhardt et al., 2013b). In short, $1 \times 105$ cells per $\mathrm{cm}^{2}$ were seeded in PLO/laminin-coated dishes and fed with N2B27 medium (1:1 DMEM/F-12 and Neurobasal medium containing 1:200 N2, 1:100 B27 without vitamin A, all from Life Technologies, and 1\% PSG), supplemented with $200 \mu \mathrm{M} \mathrm{AA,} 1 \mu \mathrm{M}$ PMA, and $100 \mathrm{ng} / \mathrm{ml}$ FGF8 (R\&D Systems) every other day for $10 \mathrm{~d}$. Thereafter cells were splitted using Accutase (Life Technologies) and reseeded with a density of $5 \times 104$ cells per $\mathrm{cm}^{2}$ on PLO/laminin-coated dishes and fed every other day for $14 \mathrm{~d}$ with N2B27 medium supplemented with $200 \mu \mathrm{M}$ AA (Sigma-Aldrich), $5 \mathrm{ng} / \mathrm{ml}$ BDNF (Promega), $10 \mathrm{ng} / \mathrm{ml}$ GDNF (Sigma-Aldrich), $1 \mathrm{ng} / \mathrm{ml} \mathrm{TGF-} \beta 3$ (Peprotech), and $250 \mu \mathrm{M}$ dbcAMP (Sigma-Aldrich). Differentiated mDANs were only used for Western blots of the G/F-actin ratio and Lyn kinase activation levels compared with MSNs.

G/F-actin Western blots. The protocol for G/F-actin Western blots was adapted from Föller et al. (2012). Mature neurons were washed with ice-cold PBS containing phosphatase inhibitor (Thermo Fisher Scientific). Cells were then incubated with extraction buffer consisting of $0.3 \%$ Triton X-100 (Thermo Fisher Scientific), 5 mm Tris/HCl (Roth), pH 7.4, $2 \mathrm{~mm}$ EGTA (Roth), $300 \mathrm{~mm}$ sucrose (Roth), $2 \mu \mathrm{M}$ phalloidin (Tocris Bioscience), and 1:100 protease inhibitor (Thermo Fisher Scientific) for 5 min on ice. The supernatant was collected and the same volume of RIPA lysis buffer was applied containing $50 \mathrm{~mm}$ Tris/ $\mathrm{HCl}, \mathrm{pH}$ 7.4, $1 \%$ Triton X-100, 1\% sodium deoxycholate (Sigma-Aldrich), 0.1\% SDS (Roth), $0.15 \mathrm{~m} \mathrm{NaCl}$ (Roth), $1 \mathrm{~mm}$ EDTA (Roth), $1 \mathrm{~mm}$ DTT (Roth), and $1 \mathrm{~mm}$ sodium orthovanadate (Sigma-Aldrich). Cells were scrapped off and incubated in the lysis buffer for $15 \mathrm{~min}$ on ice. The remaining insoluble pellet was removed by centrifugation at $10,000 \times g$ for 2 min and discarded. Globular actin (G-actin) and filamentous actin (F-actin)containing fractions were both mixed 3:1 with SDS loading buffer (Life Technologies) and $10 \mu \mathrm{l}$ was pipetted into precast $12 \%$ Bis-Tris gels (Life Technologies). For $75 \mathrm{~min}, 140 \mathrm{~V} / 60 \mathrm{~mA}$ were applied to the gels, which were then blotted on nitrocellulose membranes (Life Technologies) for 8 min using the dry blot system iBlot (Life Technologies). Membranes were blocked for $1 \mathrm{~h}$ using 5\% skim milk powder solved in PBST. Rabid polyclonal anti-actin (1:500; Cell Signaling Technology) was diluted in $1 \%$ skim milk PBST solution and incubated overnight. Samples were washed 5 times with PBST and then incubated for $1 \mathrm{~h}$ with HRPconjugated secondary antibody (1:5000; Jackson ImmunoResearch) dissolved in $1 \%$ skim milk PBST solution. Membranes were washed four times with PBST and one time with $\mathrm{ddH}_{2} \mathrm{O}$ before development was conducted using the ECL Western blot detection kit (GE Healthcare) with an LAS3000 imager (Fujifilm). Densitometry was done using TotalLab Quant software. For quantification of G/F-actin ratios by Western blots, we compared MSNs (5 separate experiments using a total of 17 healthy control and 9 ChAc clones) and mDAN ( 3 independent experiments with 16 control and 9 ChAc clones) using a Student's $t$ test with $p<0.05$ considered significant.

Lyn kinase Western blot. MSNs and mDAN (3 independent experiments with up to $3 \mathrm{ChAc}$ and control clones) were lysed in Bicina-based buffer in presence of proteasome $20 \mathrm{~S}$ inhibitor, bortezomib) as described previously (De Franceschi et al., 1997, 2011b; Franco et al., 2014). For mono-dimensional electrophoresis, proteins from neurons were solubilized in reducing sample buffer (50 mu Tris, pH 6.8, 2\% w/v SDS, $10 \%$ $\mathrm{v} / \mathrm{v}$ glycerol, $100 \mathrm{~mm} \beta$-mercaptoethanol, and a few grains of bromphenol blue). Gels were transferred to nitrocellulose membranes for immunoblot analysis with specific antibodies anti-Lyn (2732; Cell Signaling Technology), anti-phospho-Lyn (p-Lyn 396; Cell Signaling Technology), and anti-GAPDH or anti-actin (Sigma-Aldrich). Blots were developed using HRP chemiluminescence detection reagents. Densitometric analysis of band intensities was performed with Quantity One analysis software (Bio-Rad) using a Student's $t$ test with $p<0.05$ considered significant.

Cofilin and profilin Western blots. For Western blot analysis of cofilin and profilin 2a, frozen iPSC pellets were lysed with RIPA buffer containing the following (in mM): $137 \mathrm{NaCl}, 50 \mathrm{NaF}, 20$ Tris- $\mathrm{HCl}, \mathrm{pH} 7.5,25$ b-glycerophosphate, 2 EDTA, 1 sodium orthovanadate, and 1 phenylmethylsulfonylfluoride (PMSF) plus $2 \%(\mathrm{v} / \mathrm{v})$ protease inhibitor cocktail (EDTA-free; Roche), 1\% (v/v) Triton X-100, 1\% (w/v) sodium desoxycholate, and $1 \%(\mathrm{v} / \mathrm{v})$ phosphatase inhibitor cocktail 1 (Roche), sonicated, and incubated for $30 \mathrm{~min}$ on ice. Nonsoluble debris were centrifuged and protein concentration on the supernatant was determined with a BCA assay (Pierce). SDS-PAGE and Western blots were performed with equal protein amounts as described previously (Claus et al., 2003). Blots for incubation with anti-phospho-antibodies were blocked with BSA, all other blots were blocked with dried milk in TBS-Triton.

The following primary antibodies were used for Western blot analysis: mouse anti- $\beta$ III tubulin (1:3000, clone 2G10, 05-559; Millipore), mouse anti-GAPDH (1:4000; Millipore), rabbit anti-phospho (Ser-138) profilin (1:1000, PPU4791; ECM Biosciences), rabbit anti-profilin (1:1000, PPU821; ECM Biosciences), rabbit anti-phospho (hSer-3) cofilin (1: 1000, sc-12912R; Santa Cruz Biotechnology), rabbit anti-cofilin (D3FD) XP (1:1000; CST; 5175). HRP-conjugated secondary antibodies (sheep anti-mouse, 1:4000, GE Healthcare; goat anti-rabbit, 1:4000, Pierce) were used for visualization by chemiluminescence imaging using Immobilon reagent (Millipore).

Immunocytochemical staining. Cells were fixed with $4 \%$ paraformaldehyde and blocked for $45 \mathrm{~min}$ in blocking buffer (5\% goat serum, $1 \%$ BSA, $0.3 \%$ Triton X-100 in PBS). Primary antibodies were as follows: mouse monoclonal anti- $\beta$ III tubulin (TUBB3, 1:500, Millipore or 1:1000, Covance), rabbit polyclonal anti-Map2 (1:500, Cell Signaling Technology, or 1:1000, Santa Cruz Biotechnology), rabbit polyclonal anti-GABA (1: 2000; Sigma-Aldrich), mouse monoclonal anti-GABA (1:200; SigmaAldrich), rabbit polyclonal anti-DARPP32 (1:200; Santa Cruz Biotechnology), mouse monoclonal anti-Nestin (1:300; R\&D Systems), rabbit polyclonal anti-FOXG1 (1:300; Abcam), mouse monoclonal antiGAD67 (1:200; Millipore), goat polyclonal anti-SOX2 (1:200; Santa Cruz Biotechnology), mouse monoclonal anti-OCT4 (1:100; Santa Cruz Biotechnology), goat polyclonal anti-NANOG (1:50; R\&D Systems), mouse monoclonal anti-TRA1-81 (1:100; Millipore), mouse monoclonal anti- 
SSEA4 ( $1 \mu \mathrm{g} / \mathrm{ml}$; Developmental Studies Hybridoma Bank), mouse monoclonal anti-AFP (1:300; Sigma-Aldrich), and mouse monoclonal anti-SMA (1:100, Dako) were applied overnight at $4^{\circ} \mathrm{C}$. Appropriate secondary antibodies (Alexa Fluor labeled, 1:500, Life Technologies) were incubated for $1 \mathrm{~h}$ at room temperature and nuclei were counterstained with DAPI (10 mg/ml; Life Technologies) or Hoechst (Applichem), as indicated. Images were taken with an Olympus DP72 camera under an Olympus BX61 fluorescent microscope using the image-analysis software $\mathrm{Cell}^{\mathrm{F}}$ (Olympus) or on a Zeiss Axiovert Fluorescence microscope. Cell counts were performed within three randomly selected visual fields from at least three independent differentiation experiments. Cell counts for the differentiation efficiencies were performed with the Cellomics ArrayScan in an automated fashion on cultures that were fixed $2 \mathrm{~d}$ after reseeding.

Analysis of neuronal morphology and synaptic density. Cultures were stained with a $\beta$ III-tubulin antibody (1:500; Millipore), as well as an antibody directed against GABA (1:2000; Sigma-Aldrich) and images were taken with an Olympus BX60 using Olympus cellSens imaging software. The experimenter performing microscopy and analysis was blinded and images were arbitrarily selected. All automated imaging acquisition algorithms were inactivated and pictures were taken with a constant exposure time and gain for each channel, ensuring comparability between images. Images were preprocessed using a preinstalled Image J version $1.46 \mathrm{r}$ algorithm unsharp mask with a radius $(\sigma)$ of 1.0 and a mask weight of 0.6. ImageJ-based plugin NeurphologyJ (Ho et al., 2011) was used to quantify soma, neurites, attachment points, and end points. Briefly, the plugin uses two different thresholds for somata and neurites, as well as the information of the approximate neurite thickness for detection and quantification of number of somata and neurites, the area of somata and neurites, and the total neurite length within an image. Those parameters were used to normalize neurites by somata obtaining a quantitative expression for total neurite outgrowth within an image. Similarly, the end points of a neurite were normalized by soma attachment points receiving an expression for ramification. GABAergic staining was used for quantification of synaptic density using the ImageJ plugin SynapCount (version 2.0) and NeuronJ (version 1.4.3) (Meijering et al., 2004) as described previously (Hensel et al., 2016). Briefly, NeuronJ was used to trace a neurite with a distance of $30 \mu \mathrm{m}$ to the soma for a total length of at least $100 \mu \mathrm{m}$. This tracing was applied to SynapCountJ, in which GABA-positive spots along the tracing were detected within an intensity threshold. 20 images of each culture were analyzed for morphology and synaptic density and each of the different quantitative outcomes were averaged to a single value avoiding pseudo-replicates. This value was subsequently subjected to statistical analysis using a Student's $t$ test with $p<0.05$ considered significant.

Electrophysiology. Electrophysiological measurements of two ChAc patient and three control cell lines were performed after $40 \mathrm{~d}$ of differentiation in vitro from at least three independent differentiation experiments as described previously (Stanslowsky et al., 2014). In brief, patch pipettes with final resistances of 3-4 $\mathrm{M} \Omega$ were filled with the internal solution consisting of the following (in $\mathrm{mm}$ ): $153 \mathrm{KCl}, 1 \mathrm{MgCl} 2,10$ HEPES, 5 EGTA, and $2 \mathrm{Mg}$-ATP, adjusted to $\mathrm{pH} 7.3$ with $\mathrm{KOH}$ (305 mOsm). The bath solution contained the following (in $\mathrm{mm}$ ): $142 \mathrm{NaCl}, 8 \mathrm{KCl}, 1 \mathrm{CaCl} 2$, $6 \mathrm{MgCl} 2,10$ glucose, and 10 HEPES, adjusted to $\mathrm{pH} 7.4$ with $\mathrm{NaOH}(325$ mOsm). Whole-cell currents were low-pass filtered at $2.9 \mathrm{kHz}$, digitized at $10 \mathrm{kHz}$ using an EPC-10 amplifier (HEKA), and analyzed with Patch Master (HEKA). Sodium and potassium ion currents were elicited by depolarizing voltage steps in increments of $10 \mathrm{mV}$ from a holding potential of -70 to $40 \mathrm{mV}$. Miniature postsynaptic currents (mPSCs) were acquired by recording $72 \mathrm{~s}$ traces at a holding potential of $-70 \mathrm{mV}$. Action potentials (APs) were evoked in response to depolarizing current pulses in current-clamp mode. Spontaneous APs and membrane potentials were recorded by clamping the cells at $0 \mathrm{pA}$. Tetrodotoxin (TTX, $1 \mu \mathrm{M})$, tetraethyl ammonium chloride (TEA, $10 \mathrm{~mm}$ ), bicuculline (10 $\mu \mathrm{M})$, and NBQX (10 $\mu \mathrm{M}$, all purchased from Sigma-Aldrich) diluted in the bath solution were applied via gravity using a modified SF-77B perfusion fast-step system (Warner Instruments).

Drug treatment of differentiating hiPSCs. To investigate the influence of the F-actin stabilizer phallacidin (Santa Cruz Biotechnology) and the

\section{Table 1. List of oligosequences used for qRT-PCR analysis}

Gene Primer sequence $\left(5^{\prime} \rightarrow 3^{\prime}\right)$

$\mathrm{Na}_{\mathrm{v}} 1.1$

$\mathrm{Na}_{\mathrm{v}} 1.2$

$\mathrm{Na}_{\mathrm{v}} 1.3$

$\mathrm{Na}_{\mathrm{v}} 1.5$

$\mathrm{Na}_{\mathrm{v}} 1.6$

$\mathrm{Na}_{\mathrm{v}} 1.7$

$\mathrm{Na}_{\mathrm{v}} 1.8$

$\mathrm{Na}_{\mathrm{v}} 1.9$

$\mathrm{Na}_{\mathrm{x}}$

$\mathrm{Na}_{\mathrm{v}} \beta 1$

$\mathrm{Na}_{\mathrm{v}} \beta 2$

$\mathrm{Na}_{\mathrm{v}} \beta 3$

$\mathrm{Na}_{\mathrm{v}} \beta 4$

$\mathrm{Ca}_{\mathrm{v}} 1.2$

$\mathrm{Ca}_{\mathrm{v}} 1.3$

$\mathrm{Ca}_{\mathrm{v}} 2.1$

$\mathrm{Ca}_{\mathrm{v}} 2.2$

$\mathrm{Ca}_{\mathrm{v}} 2.3$

$\mathrm{Ca}_{\mathrm{v}} 3.1$

$\mathrm{Ca}_{\mathrm{v}} 3.2$

$\mathrm{Ca}_{\mathrm{v}} 3.3$

$\mathrm{Ca}_{\mathrm{v}} \alpha 2 \delta 1$

$\mathrm{Ca}_{\mathrm{v}} \alpha 2 \delta 2$

$C \mathrm{a}_{\mathrm{v}} \alpha 283$

$\mathrm{Ca}_{\mathrm{v}} \beta 1 \mathrm{~b}$

$\mathrm{Ca}_{\mathrm{v}} \beta 2 \mathrm{a}$

$\mathrm{Ca}_{\mathrm{v}} \beta 3$

$\mathrm{Ca}_{\mathrm{v}} \beta 4$

$\mathrm{Ca}_{\mathrm{v}} \gamma 2$

$\mathrm{Ca}_{\mathrm{v}} \gamma^{3}$

$\mathrm{Ca}_{\mathrm{v}} \gamma 4$

$\mathrm{Ca}_{\mathrm{v}} \gamma 5$

$\mathrm{Ca}_{\mathrm{v}} \gamma 6$

$\mathrm{Ca}_{\mathrm{v}} \gamma 7$

$\mathrm{Ca}_{\mathrm{v}} \gamma 8$

B2M

GAPDH

B-ACT

OCT4 endo

SOX2 endo

KLF4 endo

c-MYC endo

DPPA4

LIN28

OCT4 viral

SOX2 viral

KLF4 viral

C-MYC viral

MAP2

GAD67

FOXG1

Cofilin

Profilin

Synaptophysin

SYN1

DRD1

DRD2

Primer information is related to Figures 1, 3, 4, 7. fw, forward; rev, reverse.

inhibitor of the Src-family of tyrosine kinases, PP2 (Sigma-Aldrich), on electrophysiological properties of differentiating hiPSCs in vitro, separate functional experiments were performed. After $37 \mathrm{~d}$ of differentiation, cells from ChAc patients and healthy controls were treated with $100 \mathrm{~nm}$ phallacidin or $10 \mu \mathrm{M}$ PP2 for $72 \mathrm{~h}$ before analysis. Appropriate controls without drug treatments were cultured in parallel. The given drug concentrations were chosen because they had no effects on cell via-

fw: TGTGGACATCGGCGCACCTG, rev: ACACAGCCTTCAGTGAAACAAGCTT

fW: TGGCGGTTGCGCAAGACCTG, rev: GTCCTCGAAGGCCAGCGCTC

fw: CCATTGTGGGAATGTTCCTGGCAG, rev: ATGCGCCCAATACGGGCCAA

fw: CCGGTCAAGCTCCTCAGAGTGC, rev: ACACAACCATCTGTGAAACAGGCC

w: AAGCATAGGGAGCAGAAGGACCAA, rev: AGGGGCTCCCCGATCAGTTCTG W. AATCAGCTCCCAAGGCCCCCGAC, reV: AAGGCCTCAGGAGGGGGAATAAA w: TCTCCATCACAGGACTATGTCTGCC, rev: TGGTCCTTTTCCAAGACGCAGCA W. GGAGTTTGTCAAGATCCTGCGCT, rev: GGTCTTTGGTGCCCCGGCTG W. fw: CTGTCGTGGGGGGGGTCATC, rev: AGCTCACGAGACACTCCTTCTTCT fw: TCGGCAACTGACGCTCCCAGA, rev: GGCCCTTCGACCTAGTGAGGC fw: CGGACCCCGTCCTCGAAGGA, rev: CCTACGCGGATGGGGTTGGT fw: ACCGGCAGGGCAGTAGTTCCG, rev: CACAGGGGAATAGGACACGTGTGG fw: TGCTGTTCAGGAGCGCCACG, rev: CGGTGGCATTGGCCTGCTCA fw: GTGGCCCTGGGGTTCATCTTCCATA, rev: CAGGATGCCACTGAGGACCACGA fw: TCAGCCTCCCCCTGAGCGTG, rev: TTCTGCAGGACCGCATGCCG fw: GGTTCCGCGTCTCCTGCCAG, rev: AGGAAGACCCGCTCGGTGCT W: AGGCGGAGGGTGACGCCAAT, rev: CCGCTGCTGTCCAGGCCTTC fw: TGGAACCAAATAATGCACGCCAGCT, rev: CCAGGCGCACCAGGGCTTTAG fw: TCACTCGGGCCAACTGCAACA, rev: TAAACACGCGCACCGTCCGG fw: AGGTCTTCGACCCCAGCCCG, rev: GCTGAGCCCTGGCGGACAAA fw: CTGGCTCAGTGTCCTCCAGAGCT, rev: TGGGAGGATGGGTGGCCTTCC fw: TGAGGACTCGGAGGCGGGTTC, rev: GCTCTCTACTTCACGCCGGGC fw: GAGGACGTTTTCACGGAGGGAAA, rev: TGCTGTTGATGTGGGAGTTGCTCG fw: CGCACCCAAGCGAGCACTGT, rev: CCCAGAACCCAGGCCTTGCG W. TACCTCCTCCGCATCGTGCGA, rev: ATCCTGCCAGCACCGATGCAC fw: TCTGGATCGATTCACTTGCCGGG, rev: TCACAGCGAGGCCAGACCCTT fw: TCCTACTCAAAGAGGGGGCCGG, rev: AAGGCCGGGTGTGGACGGTA fw: ACTTCGGAGGGCTGTCGTTC, rev: CGAGACTGGCAGTGCGCCTC fw: TGCCTGCCGTGTGAACCATGT, rev: TGCGGCATCTTCAAACCTCCATGA fw: CTGGTAAAGTGGATATTGTTGCCAT, rev: TGGAATCATATTGGAACATGTAAACC fw: TCAAGATCATTGCTCCTCCTGAG, rev: ACATCGCTGGAAGGTGGACA fw: GGAAGGAATTGGGAACACAAAGG, rev: AACTTCACCTTCCCTCCAACCA fw: TGGCGAACCATCTCTGTGGT, rev: TGGCGAACCATCTCTGTGGT fw: ACAGTCTGTTATGCACTGTGGTTTCA, rev: CATTTGTTCTGCTTAAGGCATACTTGG fw: CCAGCAGCGACTCTGAGGA, rev: GAGCCTGCCTCTTTTCCACAG fw: GGCTCTCCCATGCATTCAAAC, rev: GGCTCTCCCATGCATTCAAAC fw: GCACACTGCCCCTCTCACAC, rev: CACCAGACCAACTGGTAATGGTAGC fw: CCTGGCCTTACACATGAAGAGACA, rev: CACCAGACCAACTGGTAATGGTAGC GCTACGGAACTCTTGTGCGTGA, rev: GCTACGGAACTCTTGTGCGTGA fw: GATGAGAATTCCTTCTCTCTCAAC, rev: AGGAGTGATGGCAGTAGACC fw: GCTACGGAACTCTTGTGCGTGA, rev: ATCCAGTGGAGAGCTGGTTG fw: CTCGTCTTCTGCGGCTCTCGG, rev: CTTGCGCTTCTTCACCTCCTCTGG fw: GTGGAACGCCTACATGGACAACC, rev: TGCCAACCAGGACACCCACC GTTTGGGGACTACTCCTCG, rev: GGCCCTTTGTTATTCTCTCGGTA fw: GACCAATACTGGCTCTGCGA, rev: AGGAACCCACCACCTCAATG fw: CTTAGGATGCTACAGACTTTGCCCTG, rev: CATGTGGGATCAGGTAAACCAGATTG fw: ACCAGAACGAGTGCATCATTGCC, rev: TGAAGGGCACGTAGAAGGAGACG

trations were chosen because 
A
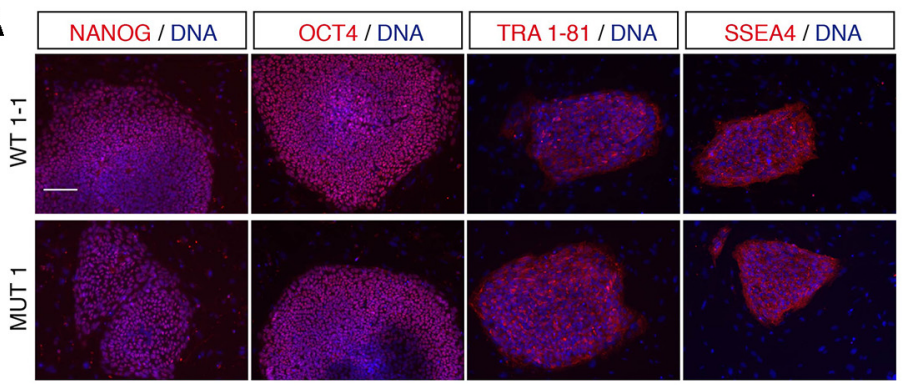

B

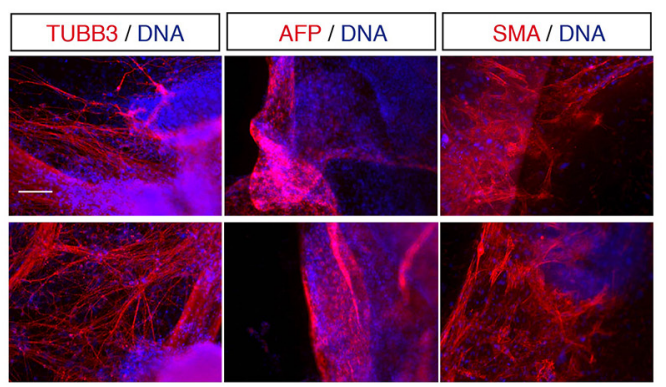

C

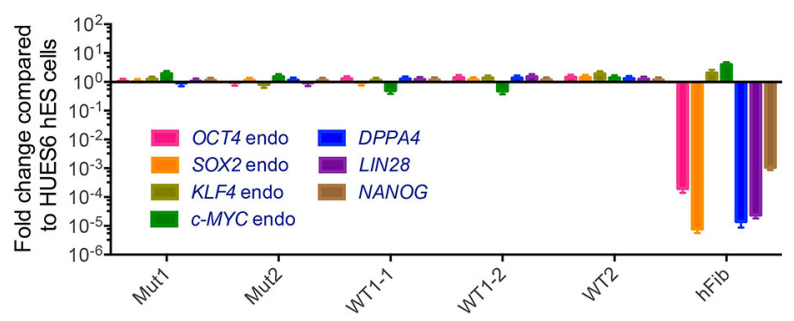

D

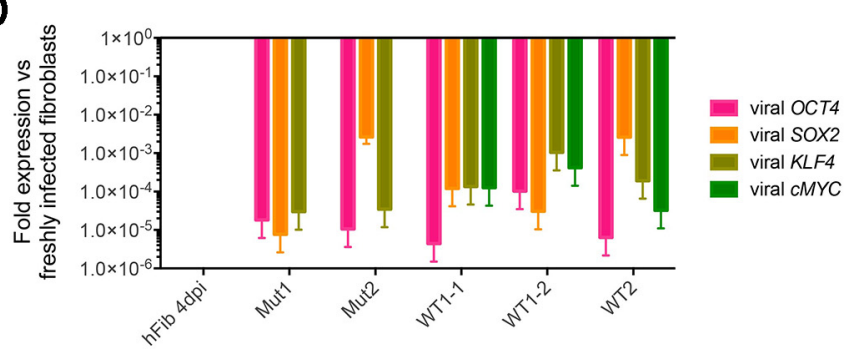

Figure 1. Characterization of hiPSC lines. A, All hiPSC lines used in this study expressed the pluripotency markers NANOG, OCT4, TRA1-81, and SSEA4 as seen by immunocytochemical stainings. $\boldsymbol{B}$, To show pluripotency, iPSC lines were differentiated in vitro into cells expressing markers of all three germ layers: ectoderm (TUBB3), endoderm (AFP), and mesoderm (SMA). For $\boldsymbol{A}$ and $\boldsymbol{B}$, WT1-1 and Mut1 are shown as representative lines. Nuclei were counterstained with Hoechst. Scale bars, $100 \mu \mathrm{m}$. C, qRT-PCR revealed that all iPSC lines expressed a comparable level of pluripotency markers as the hESC line HUES6. D, Retroviral transgenes used for reprogramming were efficiently silenced in established iPSC lines. Expression was normalized to a freshly infected human fibroblast sample $4 \mathrm{~d}$ postinfection (dpi). Data are presented as means \pm SEM using GAPDH and BACT as housekeeping genes.
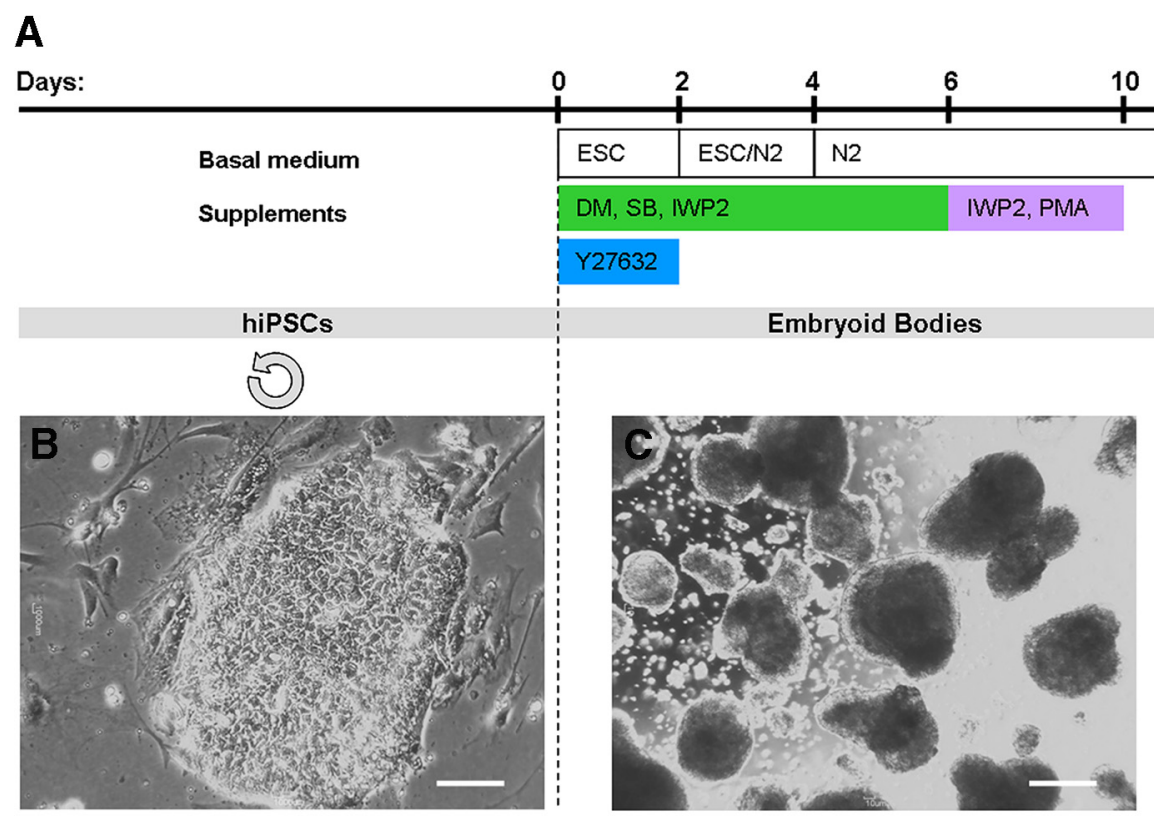

\begin{tabular}{|l|l|}
\hline $12-14$ & N2/B27 \\
\hline & BDNF, GDNF, TGF- $\beta 3$, dbcAMP \\
\hline
\end{tabular}

Medium Spiny Neurons

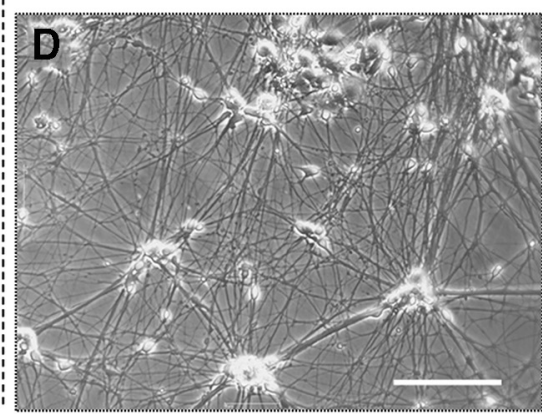

Figure 2. Sequential induction of hiPSCs toward MSNs. $\boldsymbol{A}$, Schematic summary of the differentiation procedure. $\boldsymbol{B}-\boldsymbol{D}$, Phase-contrast images during in vitro differentiation. hiPSC colonies were detached from the feeder layer and cultured in suspension as EBs in the presence of small molecules as indicated. On days 12-14, EBs were plated on Matrigel-coated cell culture dishes. Neuronal cells started to spread out and matured through the addition of various growth factors. Scale bars, $100 \mu \mathrm{m}$.

bility and proved to be efficient in former studies (De Franceschi et al., 2011a; Föller et al., 2012). The drugs were renewed with every medium change. The stock solutions were prepared by dissolving phallacidin in $\mathrm{dH}_{2} \mathrm{O}$ at a concentration of $1 \mathrm{~mm}$ and $\mathrm{PP} 2$ in DMSO at a concentration of $10 \mathrm{~mm}$.

Calcium imaging. Monitoring of cytosolic calcium transients was performed as described previously (Stanslowsky et al., 2014). Cells from ChAc patients and healthy controls were incubated for $30 \mathrm{~min}$ at $37^{\circ} \mathrm{C}$ with Fura 2-AM (Sigma-Aldrich) in standard bath solution containing the following (in mM): $140 \mathrm{NaCl}, 5 \mathrm{KCl}, 2 \mathrm{CaCl}_{2}, 10$ glucose, and $10 \mathrm{HEPES}$, adjusted to $\mathrm{pH} 7.4$ with $\mathrm{NaOH}$. Intracellular $\mathrm{Ca}^{2+}$ changes were imaged by exciting Fura 2-AM at 340 and $380 \mathrm{~nm}$ and monitoring its emission in intervals of $300 \mathrm{~ms}$ at $510 \mathrm{~nm}$ with the Life Acquisition Software (T.I.L.L. Photonics) coupled to an upright microscope (Axioskop 2 FS plus; Zeiss). Recordings were terminated by applying $50 \mathrm{~mm} \mathrm{KCl}$ to ensure the viability of the recorded cells. After background subtraction, the 340/380 nm excitation ratio for Fura 2-AM was calculated, which increases as a function of the cytosolic free $\mathrm{Ca}^{2+}\left(\left[\mathrm{Ca}^{2+}\right] \mathrm{i}\right)$. 
A

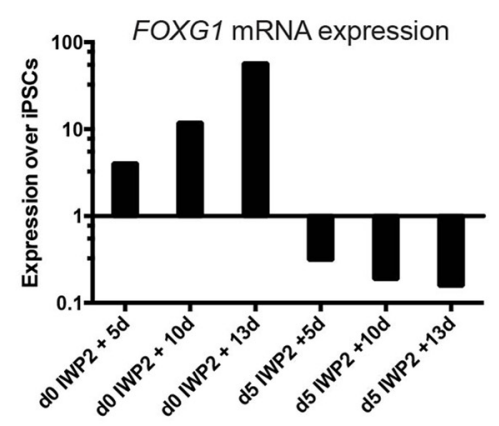

D

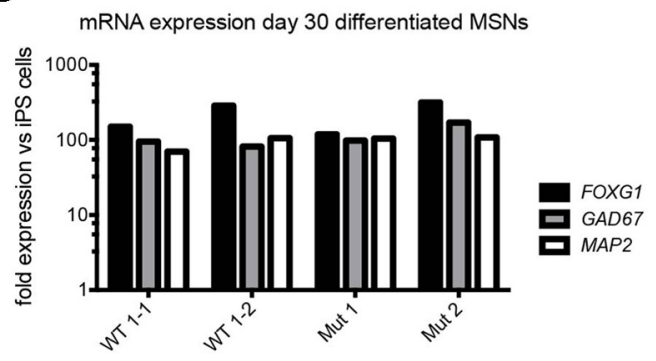

B

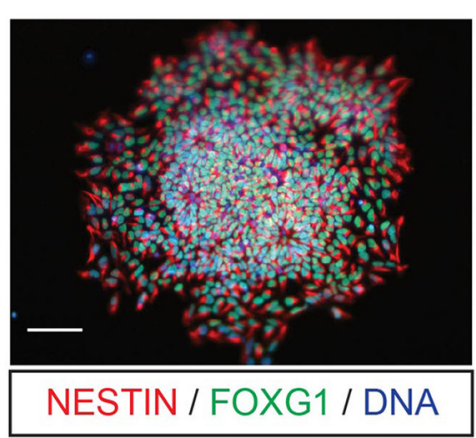

C

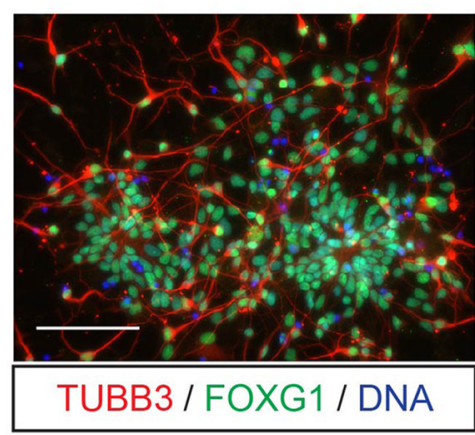

E

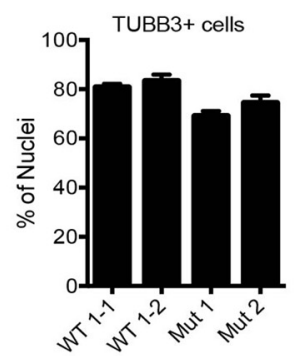

F

marker expression day 30 differentiated MSNs

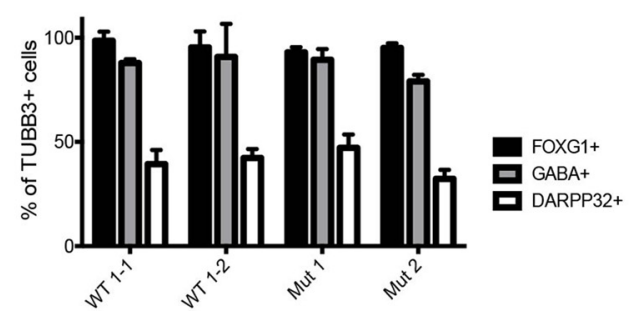

G
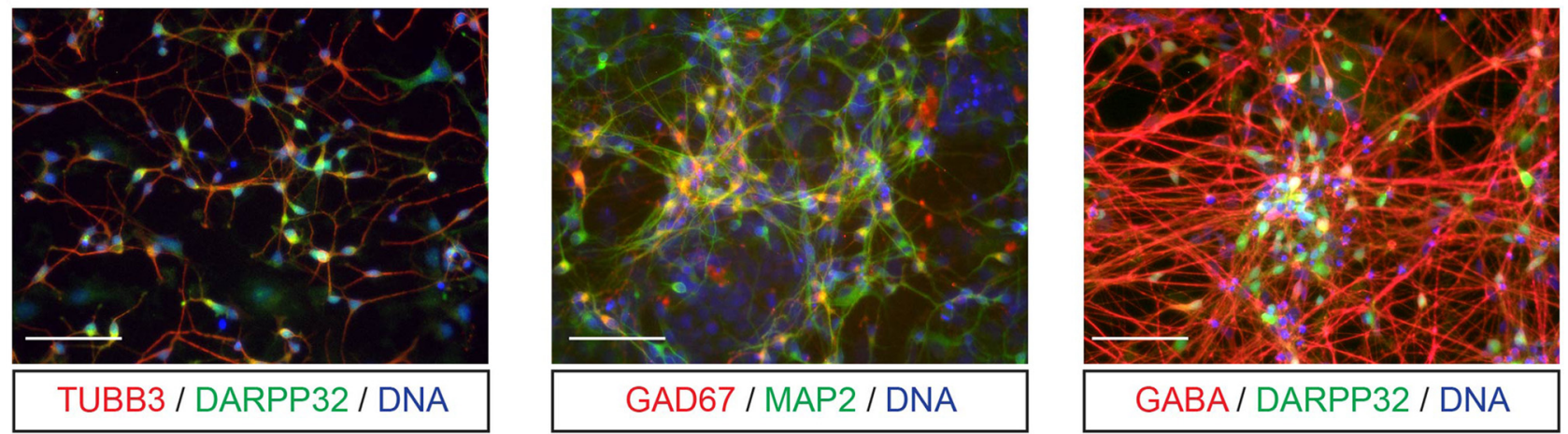

Figure 3. Differentiation of hiPSCs into MSNs. $A$, The WNT inhibitor IWP2 was added either at the beginning of differentiation or at day 5 and telencephalic identity was monitored by analyzing FOXG1 mRNA expression by qRT-PCR on day 5, 10, and 13. Only when IWP2 was added from day 0 the expression of the forebrain marker FOXG1 was strongly induced. Data were exemplarily generated with the hiPSC line WT1-2. B. When EBs were plated at day 8 of differentiation and fixed $2 \mathrm{~d}$ later, cells stained positive for the neural progenitor cell marker NESTIN and F0XG1. C, At day 21 of the differentiation process, neurons marked by the expression of TUBB3 mostly expressed FOXG1. D, At day 30, different hiPSC lines of ChAc patients (Mut 1 and 2) and controls (WT 1-1 and 1-2) showed comparable expressions of the genes FOXG1, GAD67, and MAP2 as analyzed by qRT-PCR and normalized to the average expression level in undifferentiated hiPSCS. MSNs were replated as single cells at $\sim$ day 30 . Two days later, most of the TUBB3 ${ }^{+}$neurons $(\boldsymbol{E})$ stained also positive for FOXG1 and GABA and $\sim 40 \%$ of patient and control MSNs expressed DARPP32 $(\boldsymbol{F})$. The stainings were performed in triplicate (FOXG1 and DARPP32) or duplicate (GABA). Data are shown as means \pm SEM. For $\boldsymbol{D}-\boldsymbol{F}$, the lines WT1-1, WT1-2, Mut1, and Mut2 were used. G, Mature MSNs at $\sim$ day 30 or older expressed TUBB3, DARPP32, MAP2, GAD67, and GABA, as shown by representative immunocytochemical staining. Scale bars, $100 \mu \mathrm{m}$.

Reverse transcription and $q R T-P C R$. Total RNA was extracted using the RNeasy Micro Kit (Qiagen) and reversely transcribed using oligo-dT primer and Superscript II reverse transcriptase (Life Technologies) according to manufacturers' instructions. qRT-PCR experiments were performed as described previously (Stanslowsky et al., 2014). Primer information is provided in Table 1. Target gene expressions are given as means \pm SEM, normalized to the endogenous references ( $\beta 2$ microglobulin or GAPDH and ACTB) and relative to the expression in undifferentiated iPSCs.

Statistics. Data were analyzed with GraphPad Prism 5 software if not otherwise stated. Morphological analyses, G/F-actin ratios, and Lyn kinase activation levels were calculated using a Student's $t$ test. Sodium $\left(I_{\mathrm{Na}}\right)$ and potassium $\left(I_{\mathrm{K}}\right)$ amplitudes during depolarization were compared by two-way ANOVA and Bonferroni's posttest. AP properties, synaptic activity, calcium influx, and gene expression data were analyzed statistically by a nonparametric Mann-Whitney test. All data are presented as means \pm SEM and the significance level was set at $p<0.05$.

\section{Results}

Generation of hiPSCs from ChAc patients and healthy controls

For functional analyses we generated human iPSCs from two patients harboring the mutations c. $4282 \mathrm{G}>\mathrm{C}$ and c.7806G $>\mathrm{A}$ (Mut 2) as well as confirmed absence of the chorein protein (Mut 1 and Mut 2) by Western blots. Interestingly, the ChAc patient cell line Mut 1 did not show an obvious mutation in 

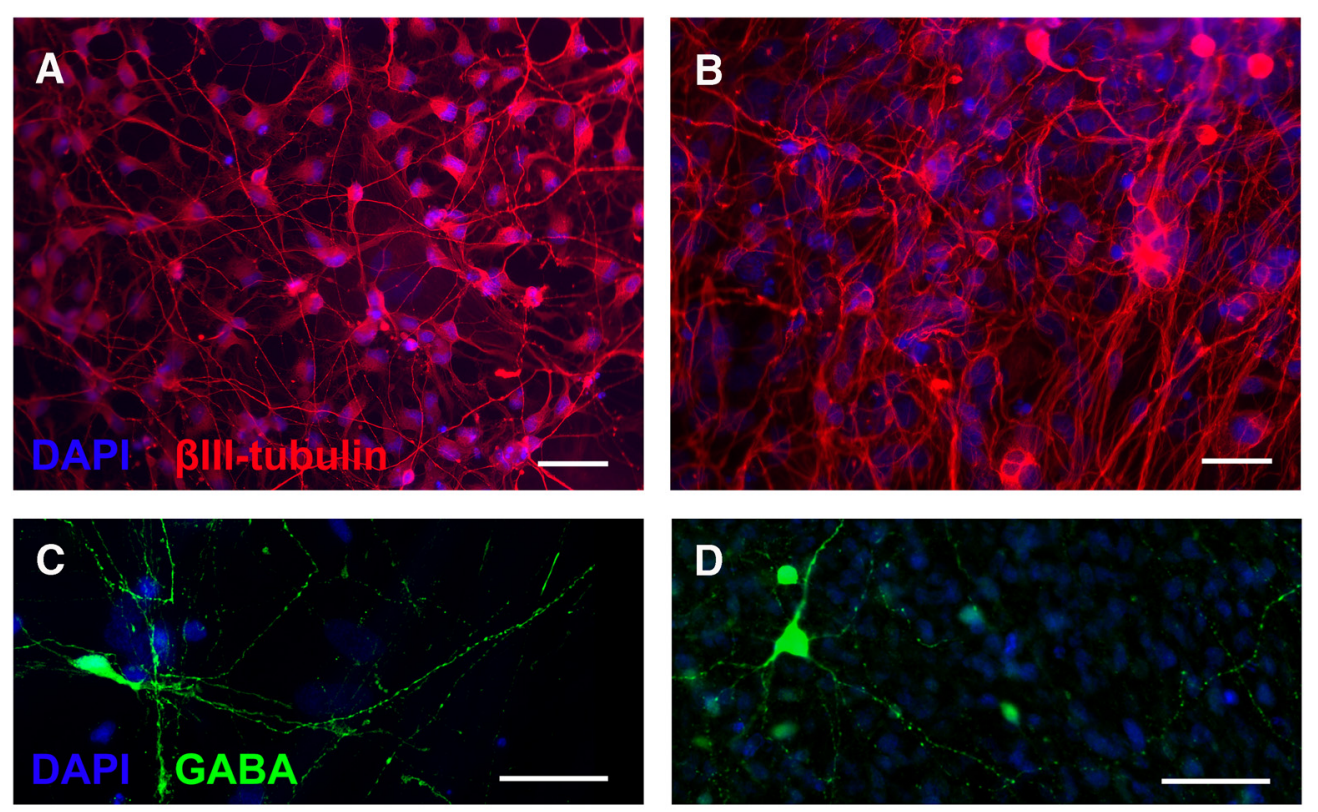

E

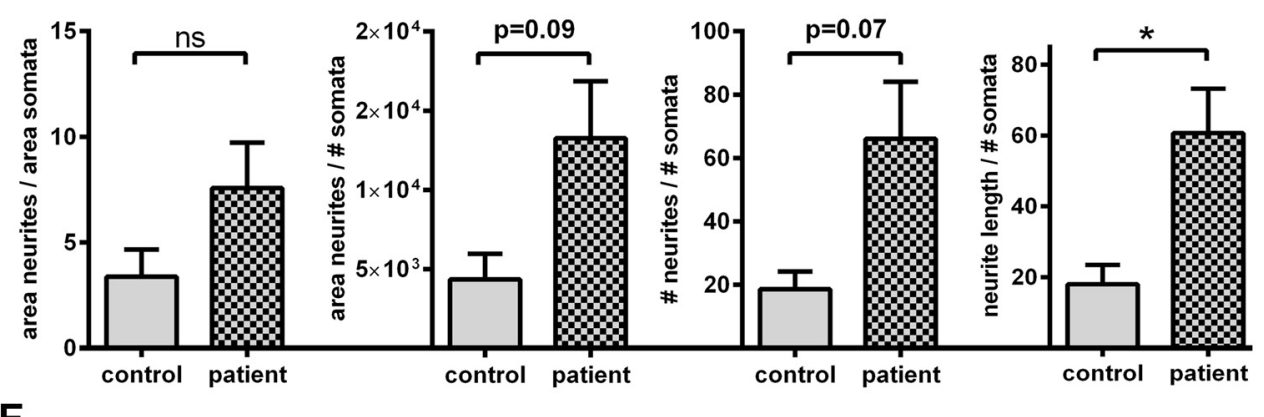

$\mathbf{F}$

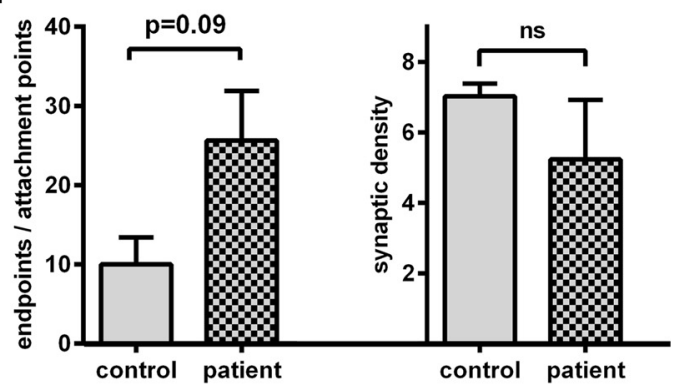

Figure 4. Neuronal morphology and GABAergic synaptic density of control and ChAc patient-derived cells. Control $(\boldsymbol{A}, \boldsymbol{C})$ and patient-derived $(\boldsymbol{B}, \boldsymbol{D})$ iPSCS were stained for neuronal marker $\beta$ III-tubulin (red) and for GABAergic synapses (green). $\beta$ III-tubulin staining was combined with the ImageJ-based software NeurphologyJ to detect neuronal somata, neurites, attachment points of neurites at the soma, and end points of neurites automatically. $\boldsymbol{E}$, Total neurite outgrowth was quantified normalizing neurites by somata. Therefore, we divided the area of the neurites by the area of the somata or the number of neurites (\# neurites) by the number of somata (\# somata). These parameters showed a tendency to be increased in patient-derived cells. In addition, total neurite length was normalized by the number of somata, which was significantly enhanced in ChAc neurons $(p<0.05$, Student's $t$ test). $\boldsymbol{F}$, The number of end points of the neurites within an image was normalized by the number of attachment points at the soma giving a quantitative expression for an increased total ramification of patient-derived cells. Moreover, we used the ImageJ-based plugin SynapCount to quantify GABAergic synapses as stained in $\boldsymbol{C}$ and $\boldsymbol{D}$. There was no significant difference in the synaptic density of ChAc neurons and controls. The bar graph gives the synaptic density as synapses per $100 \mu \mathrm{m}$ neurite (all bars show means $\pm \operatorname{SEM}, n=3$, where $n$ represents a culture seeded at different dates).

the VPS13A gene (encodes the $>3000$ aa chorein protein), although almost the complete exon sequence was investigated. However, for the generation of patient-derived iPSC lines, the loss of chorein expression was most important. As controls, we derived iPSCs from three healthy age-matched females. Clonal iPSC lines were derived from each fibroblast line. Multiple assays were applied to confirm successful reprogramming. All hiPSC lines expressed the pluripotency markers NANOG, OCT4, TRA 1-81, and SSEA4 (Fig. 1A). The pluripotency was confirmed using EB-based differentiation into cells of all three germ layers (ectoderm, mesoderm, and endoderm) as shown by immunochemical staining for TUBB3, AFP, and SMA (Fig. $1 B)$. qRT-PCR demonstrated that iPSCs expressed pluripotency markers at levels comparable to that of hESCs (Fig. 1C) and showed efficient silencing of the retroviral reprogramming constructs (Fig. 1D). Single nucleotide polymorphism array-based karyotyping was used to confirm euploidy of the generated iPSC lines (data not shown). 
A

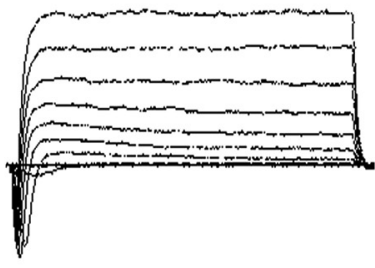

$500 \mathrm{pA}$

$5 \overline{\mathrm{ms}}$

B

- $I_{K}$ Mut ( $\left.\mathrm{n}=141\right)$

Mean Maximum

$126.6 \pm 8.0 \mathrm{pA} / \mathrm{pF}(40 \mathrm{mV})$

- $I_{K}$ WT $(\mathrm{n}=150)$

Mean Maximum

$110.1 \pm 7.3 \mathrm{pA} 7 \mathrm{pF}(40 \mathrm{mV})$

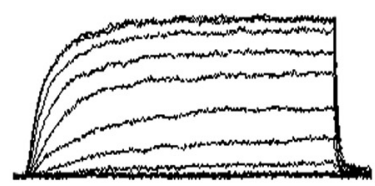

$+1 \mu \mathrm{M}$ TTX
$+1 \mu \mathrm{M}$ TEA

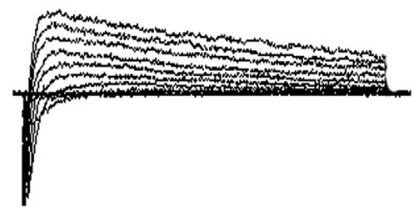

$+I_{\mathrm{Na}}$ Mut ( $\mathrm{n=127)}$

Mean Maximum

$-124.0 \pm 8.9 \mathrm{pA} / \mathrm{pF}\left(-12 \mathrm{mV}^{\text {*t* }}\right)$

$+I_{\mathrm{Na}}$ WT $(\mathrm{n}=131)$

Mean Maximum

$-104.7 \pm 7.9 \mathrm{pAvpF}\left(-4 \mathrm{mV}^{* \star *}\right)$

\section{$\mathrm{pA} / \mathrm{pF}$}

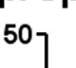

${ }^{150}$

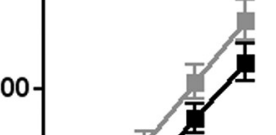

50 -

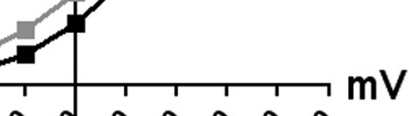

$1065^{\circ}$

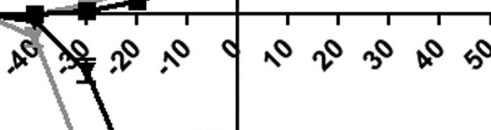


IWP2 that prevents the production of endogenous, posteriorizing WNT proteins. This strongly induced the expression of the forebrain marker FOXG1 in the differentiating EBs (Fig. 3A). Shortly after neural induction, the neuroepithelial cells were ventralized using PMA, a small-molecule agonist of the sonic hedgehog signaling pathway, and plated in maturation medium on day 8 of differentiation. At this time point, the EBs contained neuronal cells expressing the telencephalic marker FOXG1, the lateral ganglionic eminence markers GSH2 and DLX2 (data not shown), as well as the neural progenitor marker NESTIN (Fig. 3B). In the course of maturation, the cells started to express the early neuronal marker TUBB3 (Fig. 3C). Because MSNs typically have a GABAergic phenotype, the expression of glutamate decarboxylase (GAD67), the neurotransmitter GABA, and DARPP32 was assessed by qRT-PCR and immunocytochemical analysis. After $30 \mathrm{~d}$ of differentiation, the hiPSC lines analyzed showed a comparable expression of FOXG1, GAD67, and the mature neuronal marker MAP2 (Fig. 3D). High-content analysis after reseeding the cells as single cells at day 30 revealed that the different hiPSC lines matured with a good reproducibility in respect to the differentiation efficiency. Most of the TUBB3 ${ }^{+}$neurons expressed FOXG1, $\sim 80 \%$ were GABA positive, and $\sim 40 \%$ expressed DARPP32 (Fig. 3E-G). Quantitative real-time PCR analysis determined a more pronounced expression of dopamine receptor 2 (DRD2) than dopamine receptor 1 (DRD1) in ChAc and control MSNs (data not shown). Although this difference was not significant, these data suggest that the generated mixed MSN population in differentiated cultures is predominantly of the D2 type (the "indirect pathway"), which is mainly affected in neuroacanthocytosis patients (Brooks et al., 1991).

For detailed morphological analyses of MSN neurites, TUBB3 staining was combined with the ImageJ-based software NeurphologyJ to detect neuronal somata, neurites, attachment points of neurites at the soma, and end points of neurites automatically. Interestingly, ChAc patient-derived neurons displayed enhanced neurite outgrowth and ramification (Fig. $4 A, B, E, F$ ). A significant difference from controls was found for the normalized neurite length/number of somata ( $p=0.0349$, Student's $t$ test; Fig. $4 E)$. To investigate synapse formation in ChAc MSNs, we quantified GABA-positive synaptic boutons (Fig. 4C,D). Neurite tracing with the NeuronJ plugin was applied to the SynapCountJ plugin, detecting a similar synaptic density between patient and control cell lines, although ChAc MSNs showed a higher degree of ramification (Fig. $4 F$ ). The comparable number of synapses in ChAc MSNs and controls does therefore not account for differences of synaptic activity. Furthermore, in qRT-PCR, there was no significant difference in the mRNA expression of the synaptic proteins SYN1 and synaptophysin between patient-derived and control cells (data not shown).

\section{ChAc neurons show elevated synaptic activity}

Ion channel and AP properties, as well as the synaptic activity of neurons from ChAc patient and healthy control iPSC lines, were analyzed by whole-cell patch-clamp recordings to uncover potential neuronal malfunctions. Electrophysiological measurements were performed on cells with a clear neuronal morphology after $40 \mathrm{~d}$ of differentiation from a minimum of three independent differentiation experiments. In response to depolarization, all cells showed TEA-sensitive potassium outward currents and, in both patient and control groups, most of the cells generated TTX-sensitive sodium inward currents (ChAc $88.6 \pm 4.8 \%$, control $77.4 \pm 7.1 \%, p=0.24$; Fig. $5 A$ ). The maximal $I_{\mathrm{Na}}$ and $I_{\mathrm{K}}$ normalized to individual cell capacitances did not differ signifi-
Table 2. Functional properties of neurons from ChAc-iPSCs and healthy controls

\begin{tabular}{|c|c|c|c|}
\hline Functional properties & Mut $(n=141)$ & WT $(n=150)$ & $p$-values \\
\hline Cells with $\mathrm{Na}^{+}$-currents (\%) & $88.6 \pm 4.8$ & $77.4 \pm 7.1$ & 0.2415 \\
\hline Peak $\mathrm{Na}^{+}$-current (pA/pF) & $-124.0 \pm 8.9$ & $-104.7 \pm 7.9$ & 0.0930 \\
\hline Peak K ${ }^{+}$-current $(\mathrm{pA} / \mathrm{pF})$ & $126.6 \pm 8.0$ & $110.1 \pm 7.3$ & 0.0508 \\
\hline $\mathrm{Na}^{+}$channel activation $(\mathrm{mV})^{* * *}$ & $-28.2 \pm 0.7$ & $-22.4 \pm 0.8$ & $<0.0001$ \\
\hline $\mathrm{K}^{+}$channel activation $(\mathrm{mV})^{* * *}$ & $-20.3 \pm 0.9$ & $-15.3 \pm 0.9$ & 0.0001 \\
\hline Resting membrane potential $(\mathrm{mV})$ & $-35.3 \pm 0.9$ & $-32.3 \pm 1.2$ & 0.1568 \\
\hline Membrane capacitance $(\mathrm{pF})^{* * *}$ & $14.9 \pm 0.6$ & $12.5 \pm 0.7$ & 0.0006 \\
\hline Input Resistance (MOhm) & $1558.0 \pm 111.2$ & $1389.0 \pm 90.9$ & 0.4835 \\
\hline Cells with APs (\%) & $58.7 \pm 10.3$ & $45.7 \pm 9.6$ & 0.3257 \\
\hline AP amplitude $(\mathrm{mV})^{* *}$ & $49.9 \pm 1.7$ & $42.2 \pm 2.0$ & 0.0041 \\
\hline AP duration $(\mathrm{msec})^{* * *}$ & $2.2 \pm 0.1$ & $3.1 \pm 0.2$ & $<0.0001$ \\
\hline AHP amplitude $(\mathrm{mV})^{* *}$ & $19.3 \pm 0.7$ & $16.5 \pm 0.8$ & 0.0093 \\
\hline Time $t$ & $7.6=$ & $8.1 \pm 0.3$ & 0.4117 \\
\hline Cells with spontaneous APs (\%) & $13.9 \pm 3.8$ & $6.7 \pm 2.4$ & 0.1220 \\
\hline Amplitude of spont. APs (mV)** & $39.1 \pm 0.7$ & $34.6 \pm 0.6$ & 0.0012 \\
\hline Frequency of spont. APs $(\mathrm{Hz})$ & $2.4 \pm 0.5$ & $2.0 \pm 0.8$ & 0.4005 \\
\hline Cells with mPSCs (\%) ${ }^{* *}$ & $88.6 \pm 4.3$ & $69.5 \pm 5.3$ & 0.0087 \\
\hline mPSC amplitude $(\mathrm{pA})^{* * *}$ & $11.7 \pm 0.1$ & $9.5 \pm 0.4$ & $<0.0001$ \\
\hline mPSC frequency $(\mathrm{Hz})^{* * *}$ & $0.57 \pm 0.06$ & $0.30 \pm 0.03$ & $<0.0001$ \\
\hline
\end{tabular}

Voltage-gated ion channel, passive membrane, and AP properties were determined by whole-cell patch-clamp recordings. Data are given as means \pm SEM. AHP, Afterhyperpolarization.

cantly in either group (see Table 2 for means \pm SEM and sample sizes); however, the voltage dependence of $\mathrm{Na}^{+}$channel activation was shifted to more negative membrane potentials in ChAc neurons with significantly enhanced peaks at -20 and $-30 \mathrm{mV}$ (Fig. 5B). Using qRT-PCR, we observed a trend of upregulated expression of several voltage-gated $\mathrm{Na}^{+}$channel subunits that may account for the altered sodium current kinetics seen in ChAc neurons (Fig. 5C).

Current-clamp mode recordings revealed a comparable number of neurons from ChAc patients $(58.7 \pm 10.3 \%)$ and controls $(45.7 \pm 9.6 \%)$ that fired TTX-sensitive APs upon depolarizing current injection (Fig. 6A,B). Spontaneous spiking (see Fig. 6C for representative traces) was observed in a minor neuronal population (ChAc $13.9 \pm 3.8 \%$, control $6.7 \pm 2.4 \%, p=0.12$ ), with no differences in frequencies when patient and control cells were compared (Fig. 6D). Only the amplitudes of provoked and spontaneous APs were significantly higher in ChAc cells $(p=0.004$ and $p=0.001$; Fig. $6 B, D$, Table 2 ).

Next, we assessed the synaptic input received by the hiPSCderived MSNs by analyzing the spontaneous synaptic neurotransmission at a holding potential of $-70 \mathrm{mV}$. The percentage of ChAc cells showing mPSCs was significantly elevated (ChAc $88.6 \pm 4.3 \%$; control $69.5 \pm 5.3 \%, p=0.01$; Fig. $7 A$ ). We observed a nearly 2 -fold frequency increase and significantly higher amplitudes of mPSCs in ChAc neurons $(0.57 \pm 0.06 \mathrm{~Hz} ; 11.7 \pm$ $0.1 \mathrm{pA} ; n=123)$ compared with controls $(0.30 \pm 0.03 \mathrm{~Hz}, p<$ $0.0001 ; 9.5 \pm 0.4 \mathrm{pA}, p<0.0001 ; n=107)$. The origin of mPSCs was analyzed by extracellular application of the $\mathrm{GABA}_{\mathrm{A}}$ receptor antagonist bicuculline and the glutamate receptor blocker NBQX to neurons with high mPSC frequencies only. The reduction of mPSCs by application of bicuculline suggested a predominantly GABAergic synaptic input, which is consistent with the high number of striatal GABAergic MSNs in our cultures. NBQX had no significant effect on mPSCs (Fig. $7 B, C$ ).

Evaluation of the passive membrane properties in patient and control MSNs revealed no significant differences in resting membrane potentials or input resistances. Only the cell capacitances were significantly higher in ChAc neurons compared with controls (Table 2). 


\section{provoked action potentials}

A

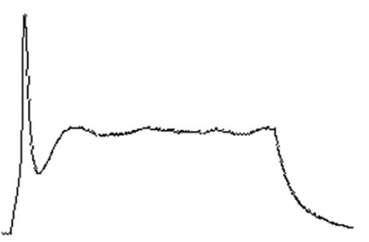

$+1 \mu \mathrm{M}$ TTX $20 \mathrm{mV}$

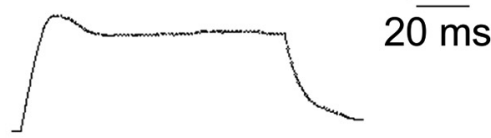

B

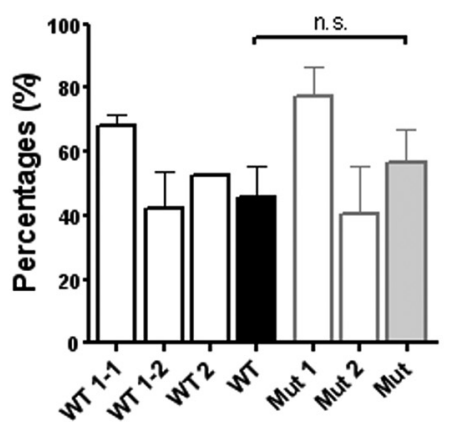

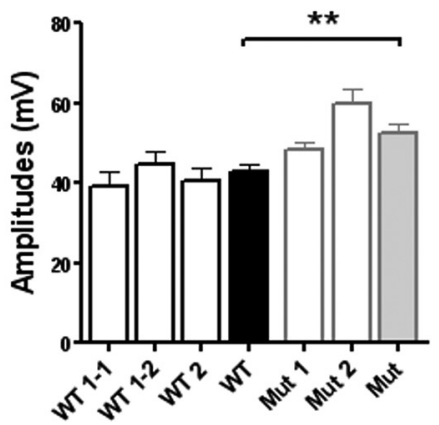

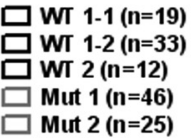

\section{spontaneous action potentials}

C

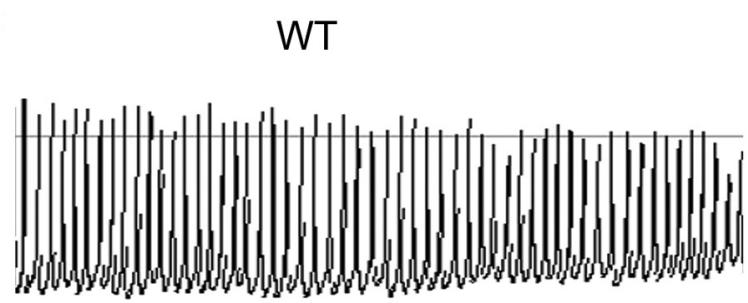

Mutant

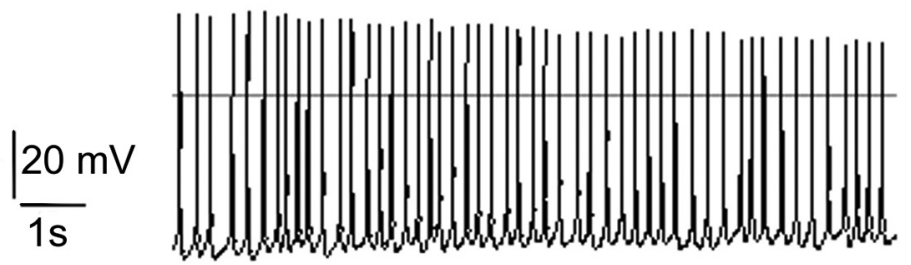

D

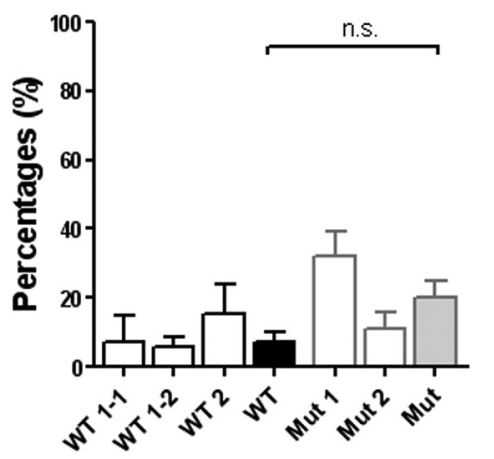

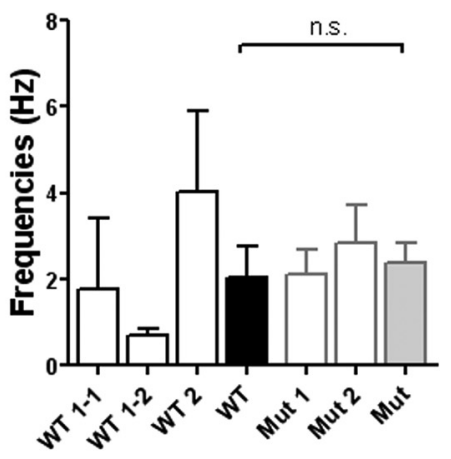

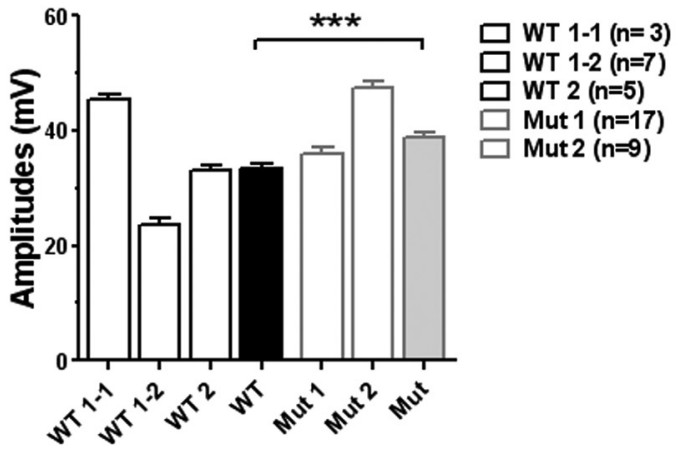

Figure 6. Elevated AP amplitudes in ChAc neurons. A, Differentiated cells from ChAc patients and healthy controls fired single APs in response to depolarizing current pulses in current-clamp mode that could be blocked by $1 \mu \mathrm{m}$ TTX. B. Although the percentage of cells with APs did not differ in either group, the AP amplitudes were significantly higher in ChAc neurons compared with controls. C, Spontaneous AP firing was measured at the neuronal membrane potential over a period of 11 s. D, Spontaneous APs were observed only in a minor cell population without significant differences in percentage or frequency, but higher amplitudes in ChAc neurons compared with controls. Data represent means \pm SEM ( $p<0.05$, Mann-Whitney test).

\section{Normal $\mathrm{Ca}^{2+}$ signaling in ChAc neurons}

Based on the observed elevated synaptic transmission in ChAc neurons and $\mathrm{Ca}^{2+}$ as a trigger for the fusion of synaptic vesicles with the plasma membrane, we investigated potential alterations in the intracellular $\mathrm{Ca}^{2+}$ signaling. The basic $\mathrm{Ca}^{2+}$ level represented by the ratio of fluorescence emission at 340 and $380 \mathrm{~nm}$ from fura-2 loaded cells was similar in ChAc cells and healthy controls. Application of the neurotransmitters GABA, acetylcholine, glutamate, and glycine induced intracellular calcium rises in comparable percentages of cells and with similar amplitudes in both groups (Fig. $8 A-C$ ). These data might exclude different neurotransmitter receptor densities as a reason for the variations in postsynaptic currents. GABA and glycine induced depolarizing $\mathrm{Ca}^{2+}$ signals in $\sim 20 \%$ of the cells, suggesting an excitatory function of these neurotransmitters in
ChAc neurons and controls because it is typically seen in fetal neurons (Wegner et al., 2008, 2012).

Neither the percentages of cells showing $\mathrm{Ca}^{2+}$ responses caused by application of $\mathrm{KCl}$ (ChAc $80.5 \pm 9.5 \%$; control $68.3 \pm$ $8.7 \%, p=0.2$ ) nor the amplitudes (ChAc $0.14 \pm 0.01, n=79$; control $0.18 \pm 0.01, n=111, p=0.2$ ) were significantly different in either group. Spontaneous calcium influx was observed in $27.0 \pm 6.5 \%$ of ChAc and $35.0 \pm 10.7 \%$ of control cells $(p=0.4)$ with similar frequencies (ChAc $0.002 \pm 0.0002, n=102$; control $0.003 \pm 0.0004, n=52, p=0.3)$ and the same mean amplitude of $0.25 \pm 0.01(p=0.9$; Fig. $8 D)$.

The expression of voltage-gated $\mathrm{Ca}^{2+}$ channels as analyzed by qRT-PCR was also not significantly different between ChAc neurons and healthy controls (Fig. 8E). 
A
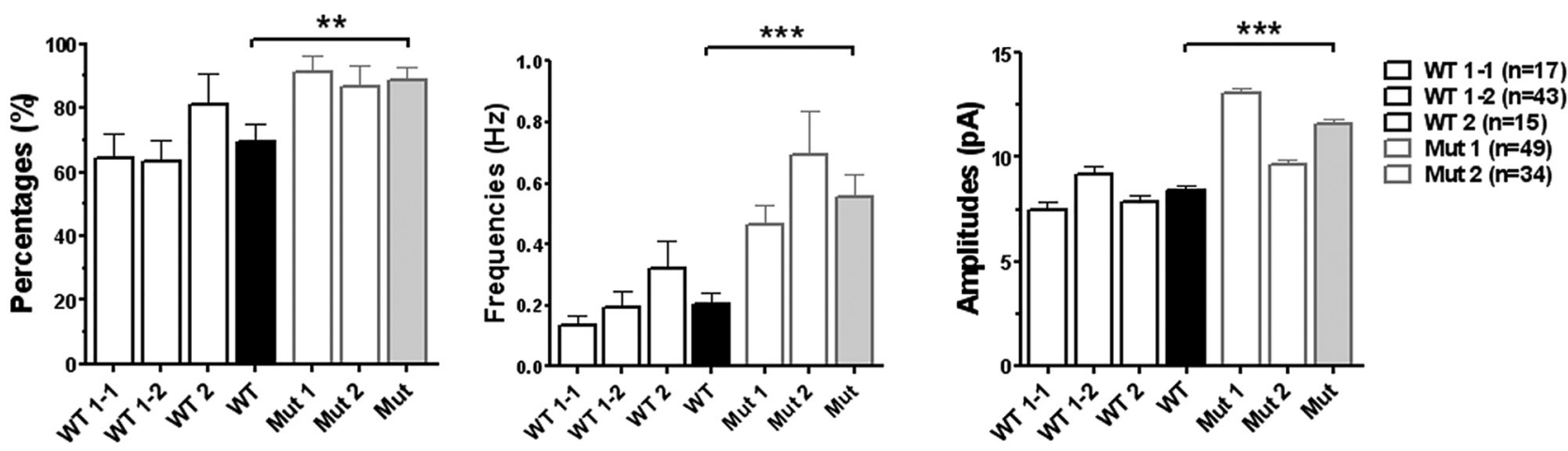

B

C

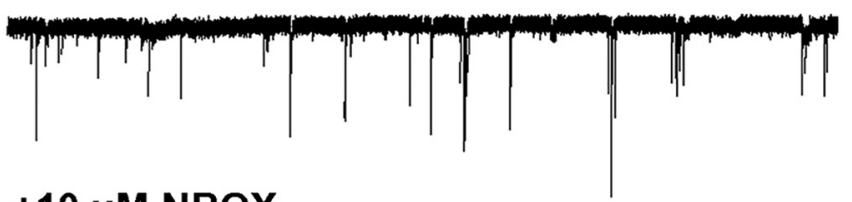

$+10 \mu \mathrm{M}$ NBQX

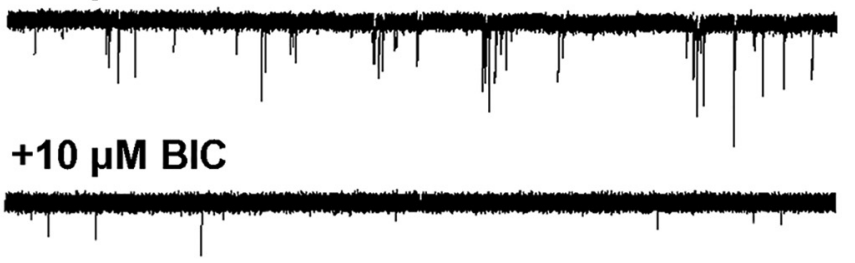

$20 \mathrm{pA} \frac{\mathrm{I}}{5 \mathrm{~s}}$

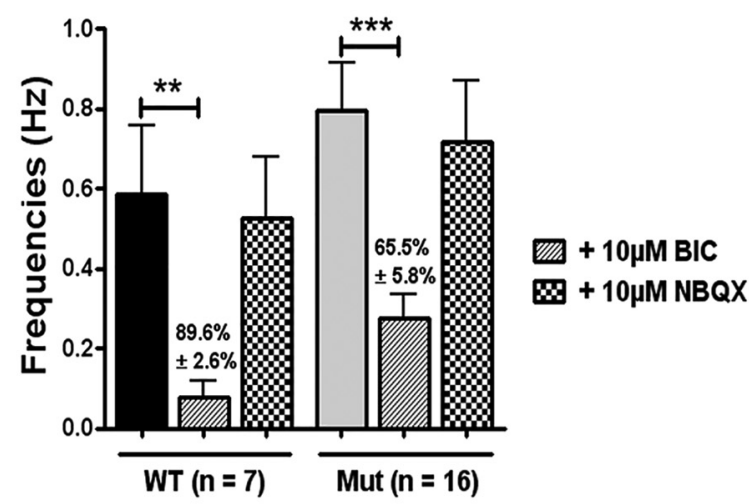

Figure 7. Enhanced spontaneous synaptic transmission in neurons derived from ChAc patient iPSCs. A, Higher percentages of ChAc neurons showed spontaneous mPSCs, which exhibited an almost 2-fold increase in frequency and a significantly higher mean amplitude in ChAc cells compared with controls, indicating a higher synaptic activity. $\boldsymbol{B}, \boldsymbol{C}$, Application of the AMPA receptor blocker NBQX reduced mPSC frequency just slightly, whereas the $\mathrm{GABA}_{A}$ receptor blocker bicucullin decreased current frequency by $66 \%$ and $90 \%$ in ChAc and control neurons, respectively, indicating a predominantly GABAergic synaptic input, which is consistent with the high number of GABAergic cells in our cultures. Data are presented as means \pm $\operatorname{SEM}(p<0.05$, Mann-Whitney test).

Decrease of synaptic activity in ChAc neurons to healthy control levels by drug treatment with phallacidin and PP2 Depolymerized cortical actin has been identified in erythrocytes from ChAc patients (Föller et al., 2012). Because the regulation of synaptic neurotransmitter release is actin dependent (Morales et al., 2000), we hypothesized that the depolymerized actin phenotype disinhibits synaptic vesicle release. To test our hypothesis, we evaluated whether stabilization of F-actin by incubating the cells with phallacidin might reverse the synaptic hyperactivity seen in ChAc neurons. Indeed, the treatment of ChAc cells with $100 \mathrm{~nm}$ phallacidin for $72 \mathrm{~h}$ (Föller et al., 2012) reduced the frequency and amplitude of synaptic currents to the level of healthy controls (Fig. 9A,B). The AP amplitudes were also reduced significantly by phallacidin treatment (Fig. 9C).

Another mechanistic explanation for the pathological synaptic currents arose from observations of increased activity of the Src-family tyrosine kinase Lyn in erythrocytes of ChAc patients (De Franceschi et al., 2011a). Elevated Lyn kinase activity weakens the connection between the actin cytoskeleton and the cell membrane (De Franceschi et al., 2011a) and might induce enhanced synaptic activity. We used the irreversible Src kinase inhibitor PP2 (10 $\mu \mathrm{M}$ for $72 \mathrm{~h}$; Williams et al., 2009; De Franceschi et al., 2011a) to treat cells before functional analyses and found a similar reduction of synaptic current frequency and amplitudes, as well as AP amplitudes, compared with phallacidin treatment (Fig. 9D-F). In both cases, the viability was not influenced, as indicated by similar numbers of TUNEL-positive cells in treated and untreated cultures after $40 \mathrm{~d}$ of differentiation (data not shown). In contrast to this regular differentiation time, a longterm cultivation ( $>3$ months) of untreated ChAc MSNs and controls revealed a significant decrease of patient-derived cells $(p<0.05$, Student's $t$ test; Fig. 10A), suggesting a beginning neurodegeneration.

We also investigated the voltage-gated sodium channel blocker and AMPA glutamate receptor antagonist riluzole for its effect on the enhanced synaptic activity in ChAc neurons. Riluzole is the only Food and Drug Administration-approved drug for the treatment of amyotrophic lateral sclerosis and has been reported to prevent excitatory neurotransmitter release from presynaptic nerve terminals by a reduction of cytosolic $\mathrm{Ca}^{2+}$, as well as stimulated transmitter clearance from the synapse (Azbill et al., 2000; Dunlop et al., 2003; Wang et al., 2004). It was also discussed as treatment for cerebellar ataxias (Romano et al., 2015). In contrast to phallacidin and PP2, incubation with $1 \mu \mathrm{M}$ riluzole during the whole differentiation period did not have significant influence on the frequency or amplitudes of mPSCs (data not shown). 
A

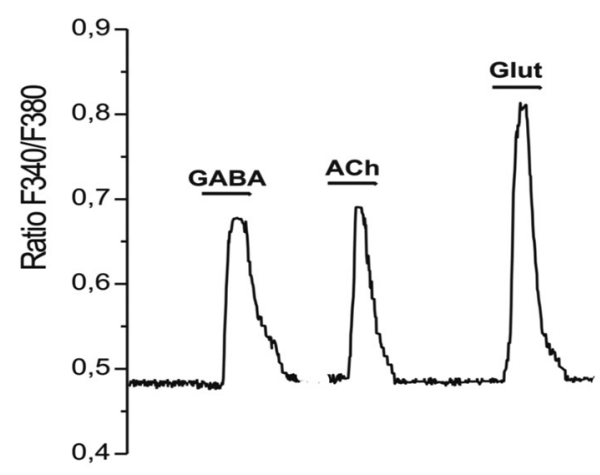

C

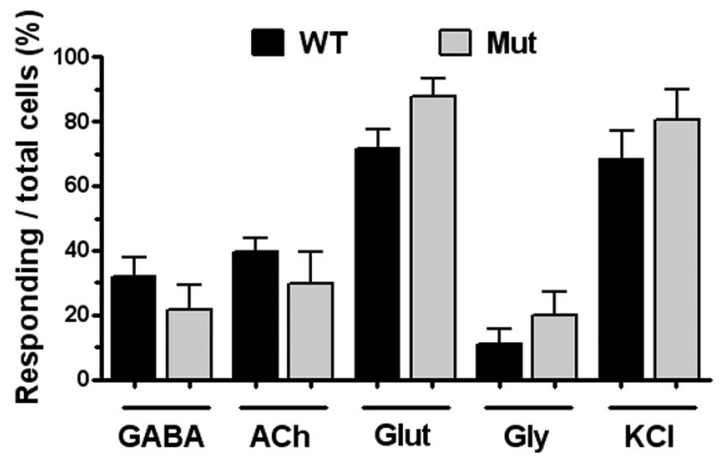

B

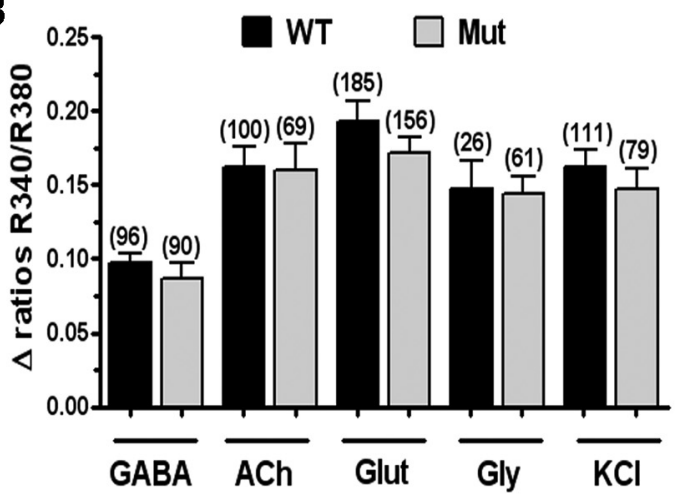

D

spontaneous $\mathrm{Ca}^{2+}$ influx

$\square$ WT (n=52) $\square$ Mut (n=102)

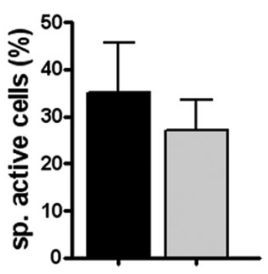

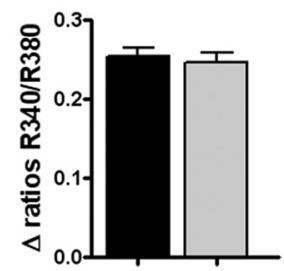

E

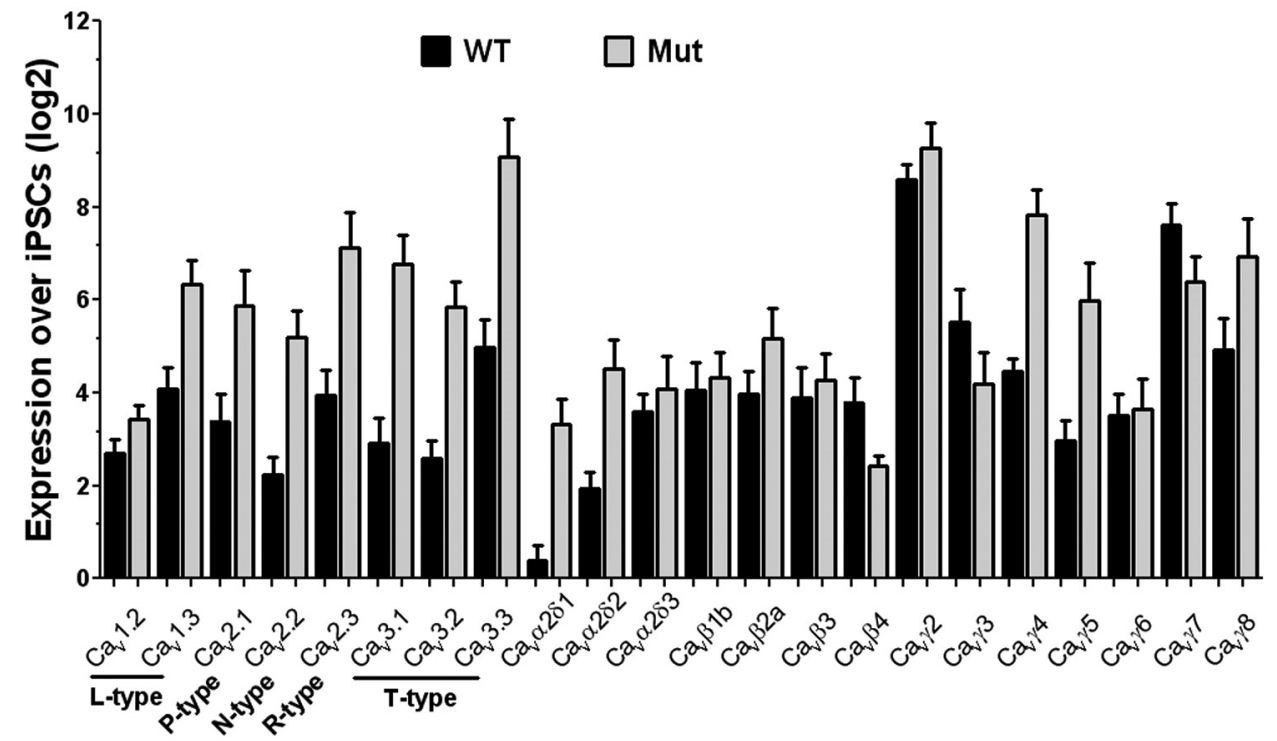

Figure 8. ChAc neurons and controls showed similar spontaneous and neurotransmitter-induced $\mathrm{Ca}^{2+}$ signaling. $A$, Representative traces of transient cytosolic $\mathrm{Ca}^{2+}$ changes induced by bath application of GABA $(100 \mu \mathrm{m})$, acetylcholine (ACh, $100 \mu \mathrm{m})$, glutamate (Glut, $50 \mu \mathrm{m})$, glycine (Gly, $100 \mu \mathrm{M})$, and KCl (50 mM) in fura-2-loaded neurons from control iPSCs. Intracellular $\mathrm{Ca}^{2+}{ }^{2+}$ changes are presented as ratios of the fluorescence signals obtained at 340 and $380 \mathrm{~nm}\left(F_{340} / F_{380}\right) \cdot B$, Summary of cytosolic $\mathrm{Ca}^{2+}$ response amplitudes normalized to the basal $\mathrm{Ca}^{2+}$ level of the investigated cells $(n)$ showed no significant differences between ChAc neurons and healthy controls. C, A similar fraction of ChAc and control cells responded to neurotransmitter application obtained from experiments as shown in $A$. Note: GABA and glycine induced depolarizing $\mathrm{Ca}^{2+}$ signals in $\sim 20 \%$ of the cells. Therefore, the GABAergic and glycinergic synaptic transmission partly have an excitatory function in ChAc neurons and controls. D, Analyzing spontaneous $\mathrm{Ca}^{2+}$ transients revealed no significant difference in the percentage of spontaneously active cells $(\sim 30 \%), \mathrm{Ca}^{2+}$ current frequency, or amplitudes in ChAc neurons compared with controls. $E$, Genomic expression of voltage-gated calcium channel subunits analyzed by qRT-PCR did not differ significantly between ChAC neurons and healthy controls. Data represent means \pm SEM ( $p<0.05$, Mann-Whitney test).

Considering our electrophysiological evidence linking F-actin stabilization and Src kinase inhibition to enhanced activity of ChAc MSNs, we sought to examine the actin network and dynamics and the activation levels of the Lyn kinase. Using qRTPCR, we measured the expression of $\beta$-actin interacting with chorein (Shiokawa et al., 2013) and did not find a significant difference between patient-derived and control cells (data not shown). Then ratios of soluble G-actin and F-actin were determined by Western blotting in differentiated patient and control neurons of multiple clones. In contrast to midbrain dopaminergic neurons (mDAN), the G/F-actin ratio of ChAc MSNs was significantly higher than in respective controls $(p<0.05$, Stu- 


\section{Phallacidin treatment}
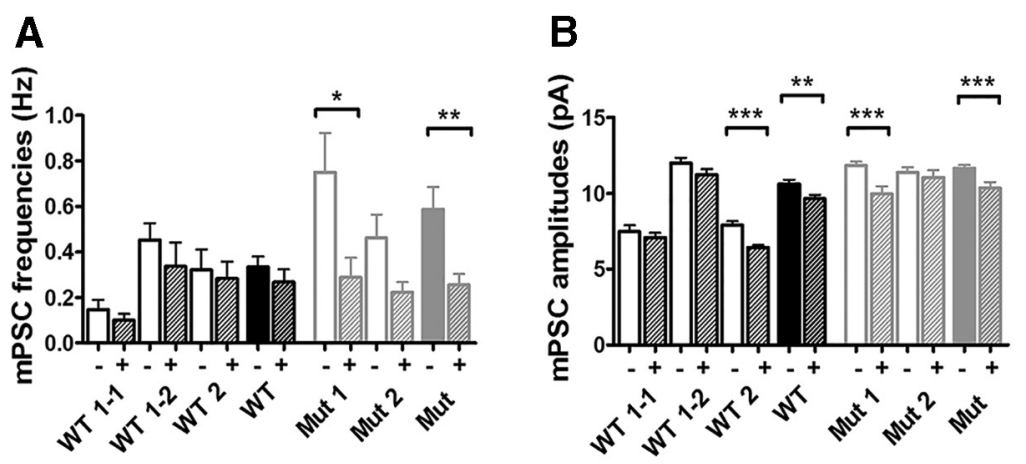

C
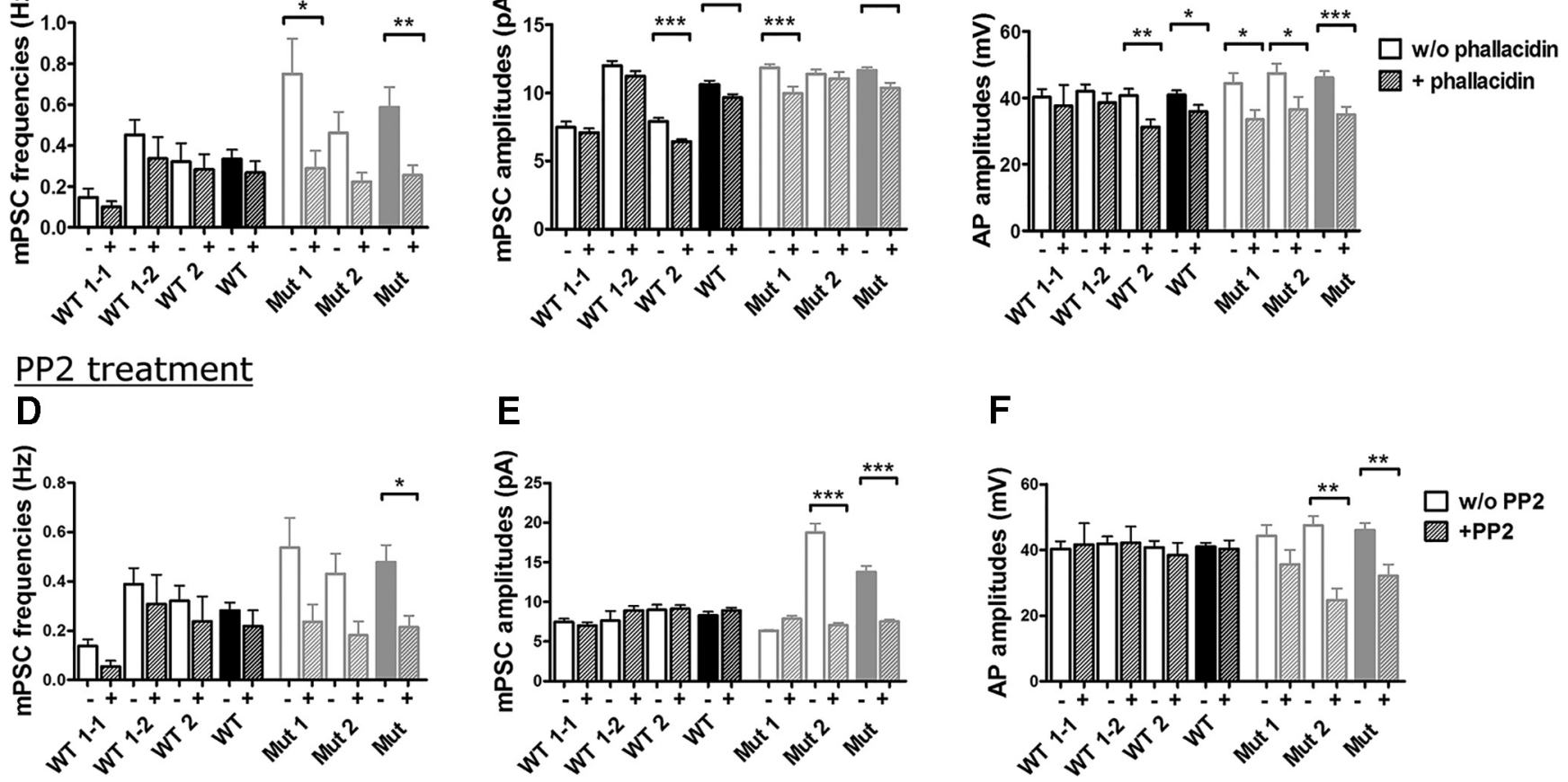

Figure 9. Treatment with the F-actin stabilizer phallacidin and the Src kinase inhibitor PP2 rescued the functional phenotype seen in ChAc neurons $(n=33-98)$. Treatment of differentiating cells with $100 \mathrm{~nm}$ phallacidin $(\boldsymbol{A}-\boldsymbol{C})$ or $10 \mu \mathrm{m}$ PP2 $(\boldsymbol{D}-\boldsymbol{F}) 72 \mathrm{~h}$ before analysis decreased the frequency and amplitudes of mPSCs to the level of control cells $(n=8-101)$. $\boldsymbol{C}, \boldsymbol{F}, \mathrm{AP}$ amplitudes were reduced significantly by phallacidin and PP2 as well. All data are given as means \pm SEM of individual cell lines and as averaged values ( $p<0.05$, Mann-Whitney test).

dent's $t$ test; Fig. 10B), suggesting a depolymerization of cortical actin comparable to erythrocytes from ChAc patients (Föller et al., 2012).

ROCK is a key player and signaling hub for regulation of the actin cytoskeleton and neuronal differentiation (da Silva et al., 2003; Nölle et al., 2011). For the analysis of actin dysregulation, we tested expression levels and phosphorylation of the ROCK downstream targets. Nonphosphorylated cofilin has an actin-severing activity, whereas phosphorylated profilin blocks its own binding to G-actin (Arber et al., 1998; Shao et al., 2008). Proteins from MSNs of two patient and control individuals were analyzed by Western blotting (Fig. 10C). Whereas expression levels and phosphorylation state of controls did not differ, one ChAc patient-derived cell line (Mut 2) showed a strong hyperphosphorylation of cofilin and MSNs from another patient (Mut 1) displayed hypophosphorylation of profilin (Fig. 10D). Although phosphorylation patterns were not uniform, these results indicate a dysregulation of the actin cytoskeleton in ChAc patient-derived MSNs.

Finally, we analyzed Lyn kinase activity in neurons derived from healthy controls and ChAc patients. As shown in Figure $10, E$ and $F$, we found significantly elevated activation levels of Lyn (phosphorylated P-Lyn396/Lyn) in MSNs (Fig. 10E) and mDANs (Fig. 10F) from ChAc subjects compared with healthy controls, which is in agreement with data reported for ChAc red cells (De Franceschi et al., 2011a). Interestingly, the MSNs as main targets of neurodegeneration in ChAc displayed a twofold increase of Lyn activity compared with mDAN.

\section{Discussion}

Our understanding of ChAc neuropathology at the cellular and molecular levels is still very limited. From skin biopsies of ChAc patients and age-matched healthy control subjects, we established a novel iPSC-based human model system to study the neuropathology of the disease. In this study, we used a differentiation protocol based on neural induction, regional patterning toward a lateral ganglionic eminence identity, and terminal differentiation to striatal MSNs (Aubry et al., 2008; Ma et al., 2012; Delli Carri et al., 2013; Golas and Sander, 2016), the cell type that is mainly affected by the neurodegenerative process, as shown by histopathological analysis and magnetic resonance imaging of ChAc patients (Hardie et al., 1991; Kutcher et al., 1999; Walterfang et al., 2008).

In many neurodegenerative diseases, such as amyotrophic lateral sclerosis, Parkinson's disease, and Huntington's disease, excitotoxicity may contribute to the pathophysiological process by which nerve cells are degenerating due to excessive synaptic transmission (Pitt et al., 2000; Van Damme et al., 2005; Dong et al., 2009). Using electrophysiological analysis of neurons from ChAc-iPSCs, we observed an elevated synaptic activity that might contribute to the striatal cell death seen in ChAc patients as the disease progresses. The spontaneous postsynaptic currents that we measured represent neurotransmitter binding events to its receptors on the postsynaptic membrane. Because abnormal neurotransmitter release or sodium channel expression and function can cause seizures, skeletal muscle paralysis, and neurodegeneration (Waxman, 2001; Wada, 2006), symptoms that are observed in ChAc patients, we studied ion channel and AP properties.

Our data showed a hyperpolarizing shift in the voltage dependence of $\mathrm{Na}^{+}$channel activation in ChAc neurons. A shift of the voltage dependence to the hyperpolarized direction has also been reported in epilepsy, in which it is believed to in- 
A

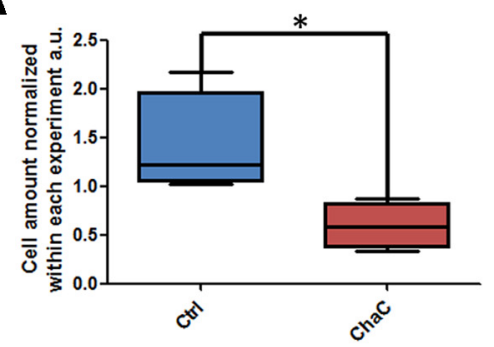

B

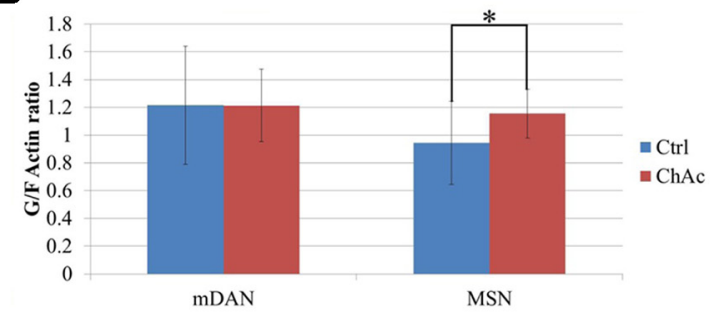

C
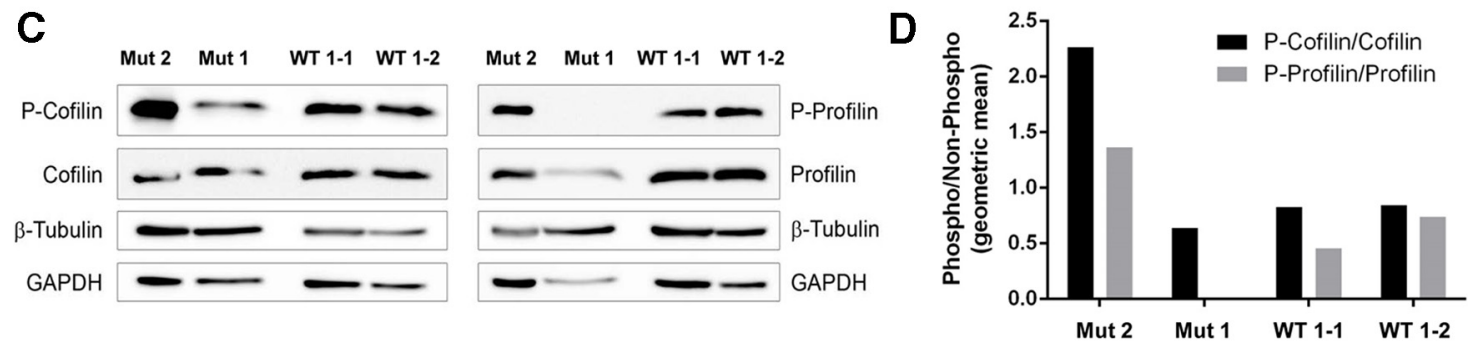

$\mathbf{E}$
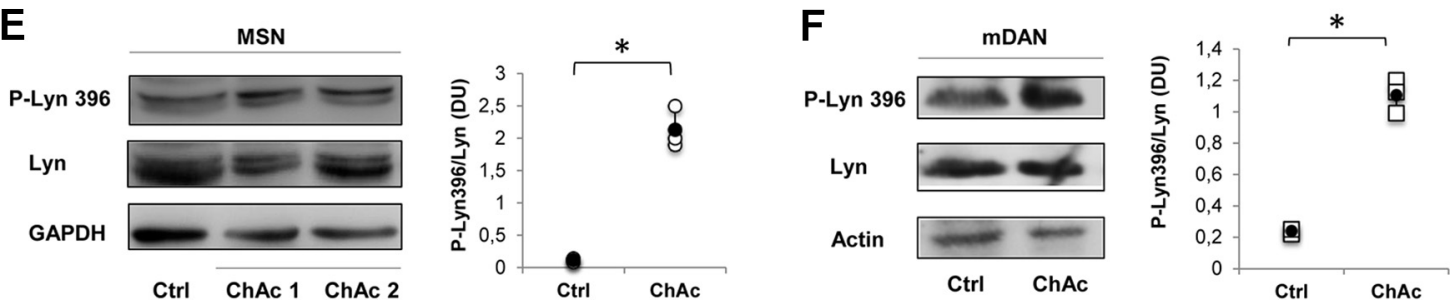

Figure 10. Actin regulation and Lyn kinase activity in differentiated neurons. A, After at least 3 months of MSN differentiation from iPSCs, cell-culture dishes of ChAc neurons ( $n=5$ clones, red) contained significantly fewer cells (data are given as Whiskers minimum to maximum, box $25 \%$ to $75 \%$, median, $p<0.05$, Student's $t$ test) than healthy controls ( $n=4$ clones, blue) when investigated with a Hoechst-based quantification assay. $B, G$ - F-actin ratio (soluble globular G-actin over filamentous F-actin) of MSNs (right bars) cultures differentiated for 6 weeks is increased significantly ( $p<0.05$, Student's $t$ test) in ChAccells ( $n=9$ clones, red) compared with healthy controls ( $n=17$ clones, blue), whereas cultivation into mDANs ( 9 ChAc and 16 control clones, left bars) did not lead to marked differences. Data represent means \pm SD. C, Western blots of patient and control MSNs were analyzed with antibodies against the Rho-kinase downstream targets cofilin (left) and profilin (right). Results show different phosphorylation patterns between patient-derived and control cells. $\boldsymbol{D}$, Phosphorylated and nonphosphorylated levels of cofilin (black) and profilin (gray) were quantitatively measured and ratios calculated. Although expression levels and phosphorylation state of controls did not differ, one ChAc cell line (Mut 2) showed a strong hyperphosphorylation of cofilin and cells from another patient (Mut 1) displayed hypophosphorylation of profilin. $\boldsymbol{E}$, Western blots with specific antibodies against active Lyn kinase (phospho-Lyn 396) and total Lyn in MSNs. The representative experiment shown is one of three separate similar experiments, each with MSNs derived from healthy controls (Ctrl) or individual ChAc patients and each with similar results. GAPDH was used as a loading control (left). Shown is a densitometric analysis of the immunoblots; data are shown as either a single experiment (empty circle) or as means \pm SD (black circle) $\left(n=3\right.$; ${ }^{*} p<0.05$, Student's $t$ test). $\boldsymbol{F}$, Western blot with specific antibodies against active Lyn (phospho-Lyn 396) and total Lyn in mDANs. The representative experiment shown is one of three separate similar experiments, each with mDANs derived from healthy controls (Ctrl) or individual ChAc subjects and each with similar results. Actin was used as a loading control (left). Shown is a densitometric analysis of the immunoblots; data are shown as either a single experiment (empty box) or as means $\pm S D$ (black circle) $\left(n=3{ }^{*} p<0.05\right.$, Student's $t$ test).

crease the channel activity and thereby may cause hyperexcitation of neurons, leading to epileptic seizures that are observed early in ChAc patients (Ogiwara et al., 2009). The earlier activation and the higher AP amplitudes in ChAc cells might be explained by a tendency of increased expression of several $\mathrm{Na}^{+}$channel subunits as seen by qRT-PCR (Hong et al., 2004; Zhan et al., 2007).

As stated above, overstimulation by increased spontaneous postsynaptic currents in ChAc neurons could result in neuronal stress and even cell death via the excessive influx of water and ions. The absence of any significant difference in ligandgated ion channel expression as measured by calcium-imaging excludes differential receptor densities as a reason for the enhanced synaptic currents. In addition, a similar synaptic density of ChAc MSNs and controls does not contribute to the increased synaptic activity in patient-derived cells. We hypothesized that a disinhibited neurotransmitter release may account for a potentially pathological synaptic hyperactivity in ChAc. Neurotransmitter release at central synapses is strongly actin dependent. Depolymerization of cortical actin promotes exocytosis and insertion of proteins into the plasma membrane (Morales et al., 2000; Malacombe et al., 2006). In epithelial cells, it has been shown that endocytosis was inhibited upon actin depolymerization (Gottlieb et al., 1993). A receptor-mediated arrest of endocytosis has also been reported by Lamaze et al. (1997) when actin polymerization was blocked in the human epidermoid carcinoma cell line A431.

Depolymerized cortical actin was found in erythrocytes from ChAc patients (Föller et al., 2012). The observed increases in the G/F-actin ratios of MSNs and erythrocytes might be a cell-specific phenomenon in ChAc, because mDANs have not yet shown this pattern of actin pathology. The implications of a disturbed actin cytoskeleton on the neuronal function can be diverse ranging over dynamics of the vesicle pool to impairment of long-term potentiation or long-term depression (Zhou et al., 2011; Lee et al., 2012). The increased G/Factin level and the altered phosphorylation of cofilin/profilin in ChAc MSNs suggest a dysregulated cortical actin network. When we treated the cells with the F-actin stabilizer phallaci- 
din, which had reversed the abnormally enhanced G/F-actin ratio in ChAc erythrocytes (Föller et al., 2012), the synaptic activity in ChAc MSNs was reduced to the level of healthy controls. These results indicate that there are cortical actin disturbances also in MSNs from ChAc patients, leading to synaptic hyperactivity and neuronal damage in the course of the disease (Morales et al., 2000). After long-term differentiation of $>3$ months, the number of ChAc patient-derived cells indeed showed a significant decrease compared with controls, suggesting a beginning process of neurodegeneration.

A similar reduction of synaptic currents was observed when the ChAc neurons were incubated with the Src kinase inhibitor PP2. Elevated activity of the Src-family tyrosine kinase Lyn, which leads to increased tyrosine phosphorylation of several membrane proteins involved in anchoring the membrane to the actin cytoskeleton, was identified in erythrocytes from ChAc patients (De Franceschi et al., 2011a). We were able to demonstrate significantly enhanced Lyn kinase activation levels in ChAc neurons. At synapses, the synaptic vesicle release is a tightly regulated process that requires the interaction of several membrane proteins and cytoskeletal elements (Fon and Edwards, 2001; Bellani et al., 2010). A weakened connection between the actin cytoskeleton and the membrane due to abnormally activated Lyn kinase might therefore result in pathologically enhanced synaptic transmission that can be attenuated by Src kinase inhibition.

We cannot exclude with certainty that neurons from ChAciPSCs mature functionally faster than cells from healthy controls, thus giving rise to an increased neurite outgrowth and ramification as well as enhanced synaptic transmission. However, the immunocytochemically detected synaptic density and the electrophysiological data, such as similar percentages of cells with sodium currents, provoked and spontaneous APs, and comparable amounts of cells with calcium responses, underlined equal differentiation and maturation abilities. Furthermore, the functional phenotype rescue seen by treatment of ChAc neurons with Src kinase inhibitor and F-actin-stabilizing compounds suggests a pathophysiological mechanism rather than a simple maturation discrepancy.

Our data indicate pathologically elevated synaptic activity in diseased ChAc neurons that is reversed to healthy control levels by treatment with the F-actin stabilizer phallacidin and the Src kinase inhibitor PP2. This was underlined by significantly increased G/F-actin ratios and Lyn kinase activation levels in patient-derived MSNs. Because Src kinases are involved in bridging the membrane to the actin cytoskeleton by membrane protein phosphorylation, our data suggest a cortical actin-dependent mechanism of this dysfunctional ChAc phenotype. This study indicates that F-actin stabilization and Src kinase inhibition represent potential treatment targets in ChAc to restore neuronal function.

\section{References}

Al-Asmi A, Jansen AC, Badhwar A, Dubeau F, Tampieri D, Shustik C, Mercho S, Savard G, Dobson-Stone C, Monaco AP, Andermann F, Andermann E (2005) Familial temporal lobe epilepsy as a presenting feature of choreoacanthocytosis. Epilepsia 46:1256-1263. CrossRef Medline

Arber S, Barbayannis FA, Hanser H, Schneider C, Stanyon CA, Bernard O, Caroni P (1998) : Regulation of actin dynamics through phosphorylation of cofilin by LIM-kinase. Nature 393:805-809. CrossRef Medline

Aubry L, Bugi A, Lefort N, Rousseau F, Peschanski M, Perrier AL (2008)
Striatal progenitors derived from human ES cells mature into DARPP32 neurons in vitro and in quinolinic acid-lesioned rats. Proc Natl Acad Sci U S A 105:16707-16712. CrossRef Medline

Azbill RD, Mu X, Springer JE (2000) Riluzole increases high-affinity glutamate uptake in rat spinal cord synaptosomes. Brain Res 871:175-180. CrossRef Medline

Bader B, Walker RH, Vogel M, Prosiegel M, McIntosh J, Danek A (2010) Tongue protrusion and feeding dystonia: a hallmark of choreaacanthocytosis. Mov Disord 25:127-129. CrossRef Medline

Bellani S, Sousa VL, Ronzitti G, Valtorta F, Meldolesi J, Chieregatti E (2010) The regulation of synaptic function by alpha-synuclein. Commun Integr Biol 3:106-109. CrossRef Medline

Brooks DJ, Ibanez V, Playford ED, Sawle GV, Leigh PN, Kocen RS, Harding AE, Marsden CD (1991) Presynaptic and postsynaptic striatal dopaminergic function in neuroacanthocytosis: a positron emission tomographic study. Ann Neurol 30:166-171. CrossRef Medline

Burgoyne RD, Cheek TR (1987) Reorganisation of peripheral actin filaments as a prelude to exocytosis. Biosci Rep 7:281-288. CrossRef Medline

Claus P, Doring F, Gringel S, Muller-Ostermeyer F, Fuhlrott J, Kraft T, Grothe C (2003) Differential intranuclear localization of fibroblast growth factor-2 isoforms and specific interaction with the survival of motoneuron protein. J Biol Chem 278:479-485. Medline

Danek A, Tison F, Rubio J, Oechsner M, Kalckreuth W, Monaco AP (2001) The chorea of McLeod syndrome. Mov Disord 16:882-889. CrossRef Medline

Da Silva JS, Medina M, Zuliani C, Di Nardo A, Witke W, Dotti CG (2003) RhoA/ROCK regulation of neuritogenesis via profilin IIa-mediated control of actin stability. J Cell Biol 162:1267-1279. CrossRef Medline

De Franceschi L, Fumagalli L, Olivieri O, Corrocher R, Lowell CA, Berton G (1997) Deficiency of Src family kinases Fgr and Hck results in activation of erythrocyte K-Cl cotransport. J Clin Invest 99:220-227. CrossRef Medline

De Franceschi L, Tomelleri C, Matte A, Brunati AM, Bovee-Geurts PH, Bertoldi M, Lasonder E, Tibaldi E, Danek A, Walker RH, Jung HH, Bader B, Siciliano A, Ferru E, Mohandas N, Bosman GJ (2011a) Erythrocyte membrane changes of chorea-acanthocytosis are the result of altered Lyn kinase activity. Blood 118:5652-5663. CrossRef Medline

De Franceschi L, Bertoldi M, De Falco L, Franco S, Ronzoni L, Turrini F, Colancecco A, Camaschella C, Cappellini MD, Iolascon A (2011b) Oxidative stress modulates heme synthesis and induces peroxiredoxin-2 as a novel cytoprotective response in $\{$ beta\} thalassemic erythropoiesis. Haematologica 96:1595-1604. CrossRef Medline

Delli Carri A, Onorati M, Lelos MJ, Castiglioni V, Faedo A, Menon R, Camnasio S, Vuono R, Spaiardi P, Talpo F, Toselli M, Martino G, Barker RA, Dunnett SB, Biella G, Cattaneo E (2013) Developmentally coordinated extrinsic signals drive human pluripotent stem cell differentiation toward authentic DARPP-32+ medium-sized spiny neurons. Development 140: 301-312. CrossRef Medline

Dobson-Stone C et al. (2002) Mutational spectrum of the CHAC gene in patients with chorea-acanthocytosis. Eur J Hum Genet 10:773-781. CrossRef Medline

Dobson-Stone C, Velayos-Baeza A, Filippone LA, Westbury S, Storch A, Erdmann T, Wroe SJ, Leenders KL, Lang AE, Dotti MT, Federico A, Mohiddin SA, Fananapazir L, Daniels G, Danek A, Monaco AP (2004) Chorein detection for the diagnosis of chorea-acanthocytosis. Ann Neurol 56: 299-302. CrossRef Medline

Dobson-Stone C, Velayos-Baeza A, Jansen A, Andermann F, Dubeau F, Robert F, Summers A, Lang AE, Chouinard S, Danek A, Andermann E, Monaco AP (2005) Identification of a VPS13A founder mutation in French Canadian families with chorea-acanthocytosis. Neurogenetics 6:151-158. CrossRef Medline

Dong XX, Wang Y, Qin ZH (2009) Molecular mechanisms of excitotoxicity and their relevance to pathogenesis of neurodegenerative diseases. Acta Pharmacol Sin 30:379-387. CrossRef Medline

Dunlop J, Beal McIlvain H, She Y, Howland DS (2003) Impaired spinal cord glutamate transport capacity and reduced sensitivity to riluzole in a transgenic superoxide dismutase mutant rat model of amyotrophic lateral sclerosis. J Neurosci 23:1688-1696. Medline

Fifková E, Delay RJ (1982) Cytoplasmic actin in neuronal processes as a possible mediator of synaptic plasticity. J Cell Biol 95:345-350. CrossRef Medline 
Föller M, Hermann A, Gu S, Alesutan I, Qadri SM, Borst O, Schmidt EM, Schiele F, vom Hagen JM, Saft C, Schöls L, Lerche H, Stournaras C, Storch A, Lang F (2012) Chorein-sensitive polymerization of cortical actin and suicidal cell death in chorea-acanthocytosis. FASEB J 26:1526-1534. CrossRef Medline

Fon EA, Edwards RH (2001) Molecular mechanisms of neurotransmitter release. Muscle Nerve 24:581-601. CrossRef Medline

Franco SS, De Falco L, Ghaffari S, Brugnara C, Sinclair DA, Matte' A, Iolascon A, Mohandas N, Bertoldi M, An X, Siciliano A, Rimmelé P, Cappellini MD, Michan S, Zoratti E, Anne J, De Franceschi L (2014) Resveratrol accelerates erythroid maturation by activation of $\mathrm{FOXO} 3$ and ameliorates anemia in beta-thalassemic mice. Haematologica 99:267-275. CrossRef Medline

Golas MM, Sander B (2016) Use of human stem cells in Huntington disease modeling and translational research. Exp Neurol 278:76-90. CrossRef Medline

Gotow T, Miyaguchi K, Hashimoto PH (1991) Cytoplasmic architecture of the axon terminal: filamentous strands specifically associated with synaptic vesicles. Neuroscience 40:587-598. CrossRef Medline

Gottlieb TA, Ivanov IE, Adesnik M, Sabatini DD (1993) Actin microfilaments play a critical role in endocytosis at the apical but not the basolateral surface of polarized epithelial cells. J Cell Biol 120:695-710. CrossRef Medline

Hardie RJ, Pullon HW, Harding AE, Owen JS, Pires M, Daniels GL, Imai Y, Misra VP, King RH, Jacobs JM (1991) Neuroacanthocytosis: a clinical, haematological and pathological study of 19 cases. Brain 114:13-49. Medline

Hensel N, Schön A, Konen T, Lübben V, Förthmann B, Baron O, Grothe C, Leifheit-Nestler M, Claus P, Haffner D (2016) Fibroblast growth factor 23 signaling in hippocampal cells: impact on neuronal morphology and synaptic density. J Neurochem 137:756-769. CrossRef Medline

Hermann A, Walker RH (2015) Diagnosis and treatment of chorea syndromes. Curr Neurol Neurosci Rep 15:514. CrossRef Medline

Ho SY, Chao CY, Huang HL, Chiu TW, Charoenkwan P, Hwang E (2011) NeurphologyJ: an automatic neuronal morphology quantification method and its application in pharmacological discovery. BMC Bioinformatics 12:230. CrossRef Medline

Hong S, Morrow TJ, Paulson PE, Isom LL, Wiley JW (2004) Early painful diabetic neuropathy is associated with differential changes in tetrodotoxin-sensitive and -resistant sodium channels in dorsal root ganglion neurons in the rat. J Biol Chem 279:29341-29350. CrossRef Medline

Honisch S, Gu S, Vom Hagen JM, Alkahtani S, Al Kahtane AA, Tsapara A, Hermann A, Storch A, Schöls L, Lang F, Stournaras C (2015) Chorein sensitive arrangement of cytoskeletal architecture. Cell Physiol Biochem 37:399-408. CrossRef Medline

Jung HH, Danek A, Walker RH (2011) Neuroacanthocytosis syndromes. Orphanet J Rare Dis 6:68. CrossRef Medline

Kutcher JS, Kahn MJ, Andersson HC, Foundas AL (1999) Neuroacanthocytosis masquerading as Huntington's disease: CT/MRI findings. J Neuroimaging 9:187-189. CrossRef Medline

Lamaze C, Fujimoto LM, Yin HL, Schmid SL (1997) The actin cytoskeleton is required for receptor-mediated endocytosis in mammalian cells. J Biol Chem 272:20332-20335. CrossRef Medline

Lee JS, Ho WK, Lee SH (2012) Actin-dependent rapid recruitment of reluctant synaptic vesicles into a fast-releasing vesicle pool. Proc Natl Acad Sci U S A 109:E765-774. CrossRef Medline

Ma L, Hu B, Liu Y, Vermilyea SC, Liu H, Gao L, Sun Y, Zhang X, Zhang SC (2012) Human embryonic stem cell-derived GABA neurons correct locomotion deficits in quinolinic acid-lesioned mice. Cell Stem Cell 10: 455-464. CrossRef Medline

Malacombe M, Bader MF, Gasman S (2006) Exocytosis in neuroendocrine cells: new tasks for actin. Biochim Biophys Acta 1763:1175-1183. CrossRef Medline

Meijering E, Jacob M, Sarria JC, Steiner P, Hirling H, Unser M (2004) Design and validation of a tool for neurite tracing and analysis in fluorescence microscopy images. Cytometry A 58:167-176. Medline

Morales M, Colicos MA, Goda Y (2000) Actin-dependent regulation of neurotransmitter release at central synapses. Neuron 27:539-550. CrossRef Medline

Muallem S, Kwiatkowska K, Xu X, Yin HL (1995) Actin filament disassem- bly is a sufficient final trigger for exocytosis in nonexcitable cells. J Cell Biol 128:589-598. CrossRef Medline

Nölle A, Zeug A, van Bergeijk J, Tönges L, Gerhard R, Brinkmann H, Al Rayes S, Hensel N, Schill Y, Apkhazava D, Jablonka S, O'mer J, Srivastav RK, Baasner A, Lingor P, Wirth B, Ponimaskin E, Niedenthal R, Grothe C, Claus $P$ (2011) The spinal muscular atrophy disease protein SMN is linked to the Rho-kinase pathway via profilin. Hum Mol Genet 20:48654878. CrossRef Medline

Ogiwara I, Ito K, Sawaishi Y, Osaka H, Mazaki E, Inoue I, Montal M, Hashikawa T, Shike T, Fujiwara T, Inoue Y, Kaneda M, Yamakawa K (2009) De novo mutations of voltage-gated sodium channel alphaII gene SCN2A in intractable epilepsies. Neurology 73:1046-1053. CrossRef Medline

Park JS, Neiman AM (2012) VPS13 regulates membrane morphogenesis during sporulation in Saccharomyces cerevisiae. J Cell Sci 125:3004-3011. CrossRef Medline

Pitt D, Werner P, Raine CS (2000) Glutamate excitotoxicity in a model of multiple sclerosis. Nat Med 6:67-70. CrossRef Medline

Reinhardt P et al. (2013a) Genetic correction of a LRRK2 mutation in human iPSCs links parkinsonian neurodegeneration to ERK-dependent changes in gene expression. Cell Stem Cell 12:354-367. CrossRef Medline

Reinhardt P, Glatza M, Hemmer K, Tsytsyura Y, Thiel CS, Höing S, Moritz S, Parga JA, Wagner L, Bruder JM, Wu G, Schmid B, Röpke A, Klingauf J, Schwamborn JC, Gasser T, Schöler HR, Sterneckert J (2013b) Derivation and expansion using only small molecules of human neural progenitors for neurodegenerative disease modeling. PloS one 8:e59252. CrossRef Medline

Romano S, Coarelli G, Marcotulli C, Leonardi L, Piccolo F, Spadaro M, Frontali M, Ferraldeschi M, Vulpiani MC, Ponzelli F, Salvetti M, Orzi F, Petrucci A, Vanacore N, Casali C, Ristori G (2015) Riluzole in patients with hereditary cerebellar ataxia: a randomised, double-blind, placebocontrolled trial. Lancet Neurol 14:985-991. CrossRef Medline

Schmidt EM, Schmid E, Münzer P, Hermann A, Eyrich AK, Russo A, Walker B, Gu S, vom Hagen JM, Faggio C, Schaller M, Föller M, Schöls L, Gawaz M, Borst O, Storch A, Stournaras C, Lang F (2013) Chorein sensitivity of cytoskeletal organization and degranulation of platelets. FASEB J 27: 2799-2806. CrossRef Medline

Shao J, Welch WJ, Diprospero NA, Diamond MI (2008) Phosphorylation of Profilin by ROCK1 regulates polyglutamine aggregation. Mol Cell Biol 28:5196-5208. CrossRef Medline

Shiokawa N, Nakamura M, Sameshima M, Deguchi A, Hayashi T, Sasaki N, Sano A (2013) Chorein, the protein responsible for choreaacanthocytosis, interacts with $\beta$-adducin and $\beta$-actin. Biochem Biophys Res Commun 441:96-101. CrossRef Medline

Stanslowsky N, Haase A, Martin U, Naujock M, Leffler A, Dengler R, Wegner F (2014) Functional differentiation of midbrain neurons from human cord blood-derived induced pluripotent stem cells. Stem Cell Res Ther 5:35. CrossRef Medline

Tomemori Y, Ichiba M, Kusumoto A, Mizuno E, Sato D, Muroya S, Nakamura M, Kawaguchi H, Yoshida H, Ueno S, Nakao K, Nakamura K, Aiba A, Katsuki M, Sano A (2005) A gene-targeted mouse model for choreaacanthocytosis. J Neurochem 92:759-766. CrossRef Medline

Ueno S, Maruki Y, Nakamura M, Tomemori Y, Kamae K, Tanabe H, Yamashita Y, Matsuda S, Kaneko S, Sano A (2001) The gene encoding a newly discovered protein, chorein, is mutated in chorea-acanthocytosis. Nat Genet 28:121-122. CrossRef Medline

Van Damme P, Dewil M, Robberecht W, Van Den Bosch L (2005) Excitotoxicity and amyotrophic lateral sclerosis. Neurodegener Dis 2:147-159. Medline

Velayos-Baeza A, Vettori A, Copley RR, Dobson-Stone C, Monaco AP (2004) Analysis of the human VPS13 gene family. Genomics 84:536-549. CrossRef Medline

Vitale ML, Seward EP, Trifaró JM (1995) Chromaffin cell cortical actin network dynamics control the size of the release-ready vesicle pool and the initial rate of exocytosis. Neuron 14:353-363. CrossRef Medline

Wada A (2006) Roles of voltage-dependent sodium channels in neuronal development, pain, and neurodegeneration. J Pharmacol Sci 102:253268. CrossRef Medline

Walterfang M, Yucel M, Walker R, Evans A, Bader B, Ng A, Danek A, Mocellin R, Velakoulis D (2008) Adolescent obsessive compulsive disorder heralding chorea-acanthocytosis. Mov Disord 23:422-425. CrossRef Medline

Wang SJ, Wang KY, Wang WC (2004) Mechanisms underlying the riluzole 
inhibition of glutamate release from rat cerebral cortex nerve terminals (synaptosomes). Neuroscience 125:191-201. CrossRef Medline

Waxman SG (2001) Transcriptional channelopathies: an emerging class of disorders. Nat Rev Neurosci 2:652-659. Medline

Wegner F, Kraft R, Busse K, Härtig W, Schaarschmidt G, Schwarz SC, Schwarz J, Hevers W (2008) Functional and molecular analysis of GABA receptors in human midbrain-derived neural progenitor cells. J Neurochem 107:1056-1069. CrossRef Medline

Wegner F, Kraft R, Busse K, Härtig W, Ahrens J, Leffler A, Dengler R, Schwarz J (2012) Differentiated human midbrain-derived neural progenitor cells express excitatory strychnine-sensitive glycine receptors containing $\alpha 2 \beta$ subunits. PLoS One 7:e36946. CrossRef Medline
Williams NK, Lucet IS, Klinken SP, Ingley E, Rossjohn J (2009) Crystal structures of the Lyn protein tyrosine kinase domain in its Apoand inhibitor-bound state. J Biol Chem 284:284-291. CrossRef Medline

Zhan RZ, Nadler JV, Schwartz-Bloom RD (2007) Impaired firing and sodium channel function in CA1 hippocampal interneurons after transient cerebral ischemia. J Cereb Blood Flow Metab 27:1444-1452. CrossRef Medline

Zhou Z, Hu J, Passafaro M, Xie W, Jia Z (2011) GluA2 (GluR2) regulates metabotropic glutamate receptor-dependent long-term depression through $\mathrm{N}$-cadherin-dependent and cofilin-mediated actin reorganization. J Neurosci 31:819-833. CrossRef Medline 